DEPARTMENT OF THE INTERIOR

UNITED STATES GEOLOGICAL SURVEY

CHARLES D. WALCOTT, DIRECTOR

\title{
EXPERIMENTS
}

ON

\section{STEEL-CONCRETE PIPES ON \\ A WORKING SCALE}

BY

JOHN H. QUINTON

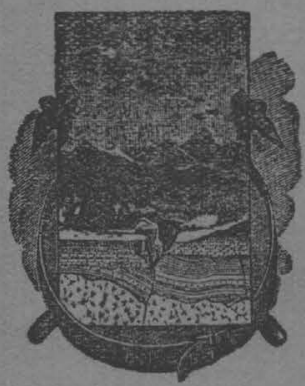

WASHINGTON

GOVERNMENT PRINTING OFFICE

1905 

DEPARTMENT OF THE INTERIOR

UNITED STATES GEOLOGICAL SURVEY

CHARLES D. WALCOTT, DIRECTOR

\section{EXPERIMENTS}

ON

\section{STEEL-CONCRETE PIPES ON \\ A WORKING SCALE}

BY

JOHN H. QUINTON

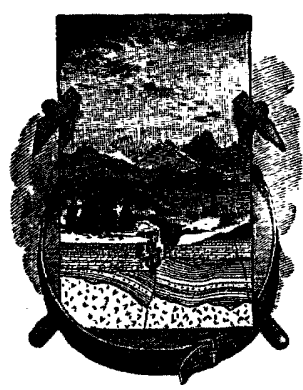

WASHINGTON

GOVER NMET PRINTING OFFICE

1905 



\section{CONTENTS.}

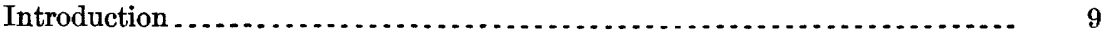

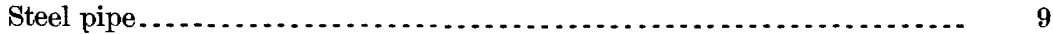

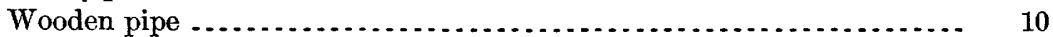

Steel-concrete pipe .............................................. 11

Composition and construction of pipes :............................. 11

Composition of test pipes. . . . . . . . . . . . . .

Pipe No. 1................................................ 13

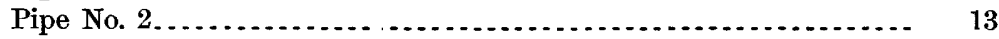

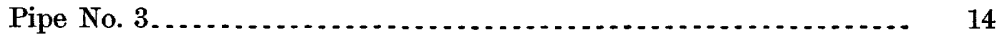

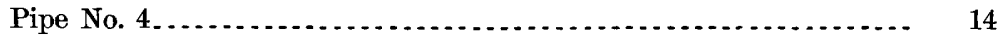

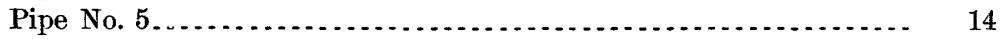

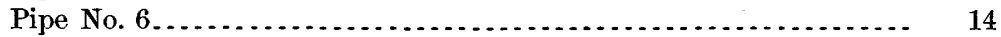

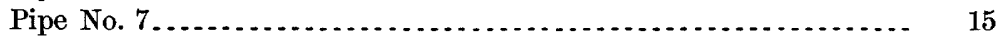

Method of pipe construction ................................. 15

Apparatus used for testing pipes. . . . . . . . .

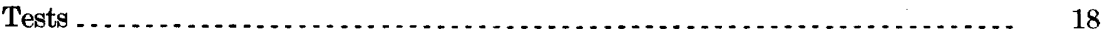

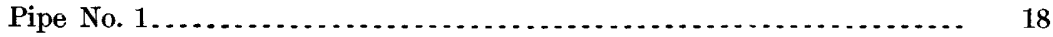

Plaster linings................................................... 18

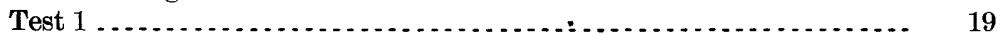

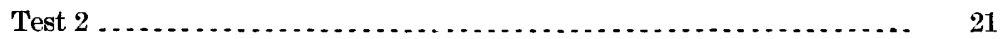

Pipe No. 2. ................................................... 21

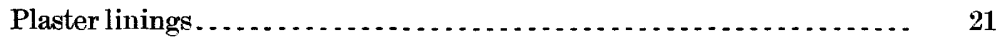

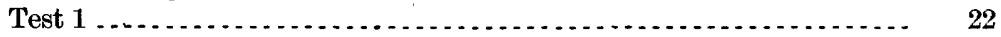

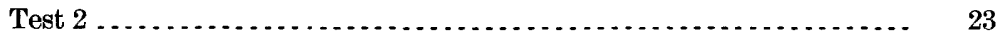

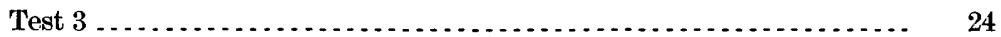

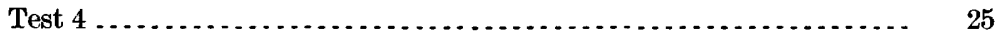

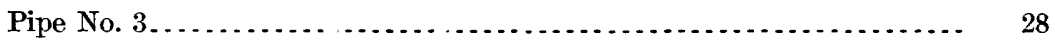

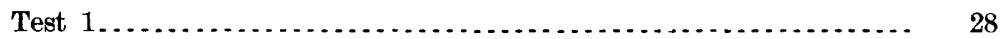

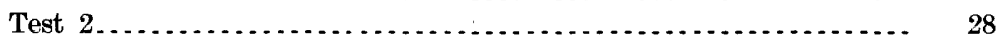

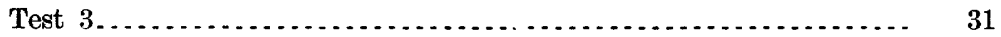

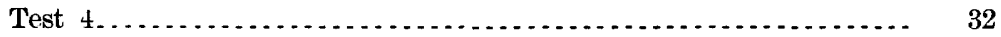

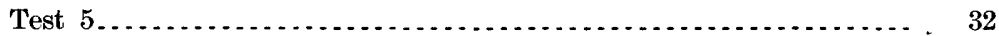

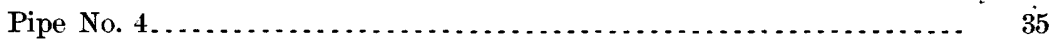

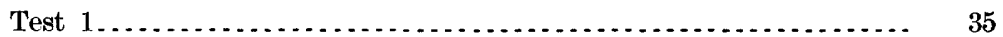

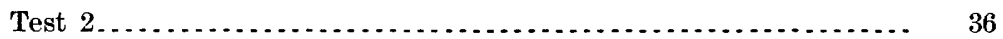

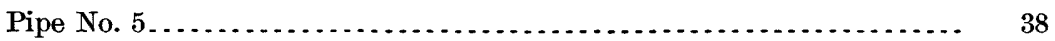

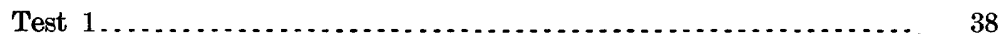

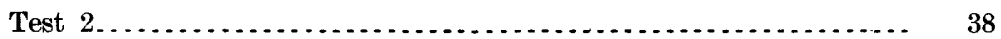

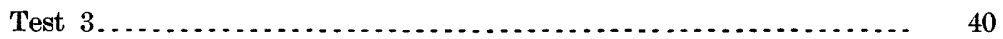

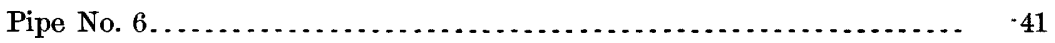

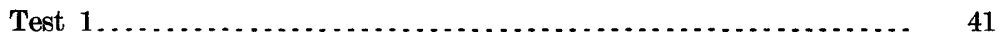

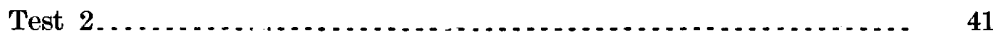

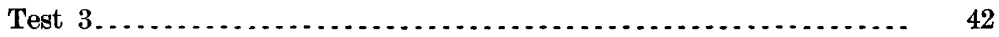


Tests-Continued. Page.

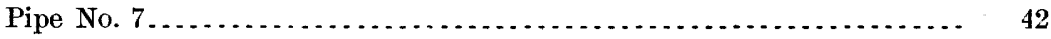

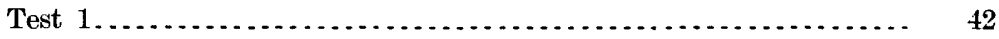

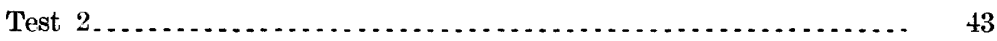

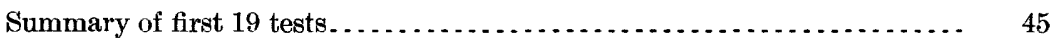

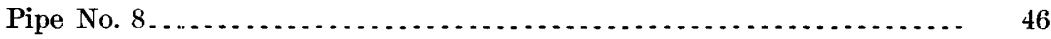

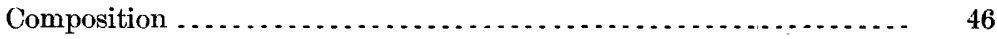

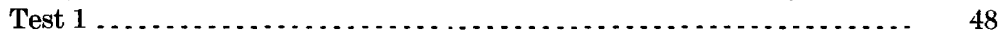

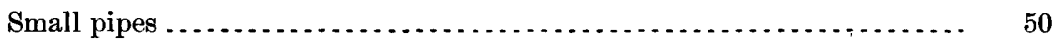

Pipe A, Mixture No. 1............................... 52

Pipe B, Mixture No. 1................................. 52

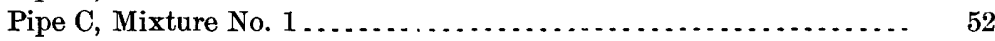

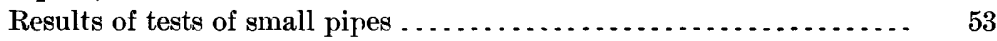

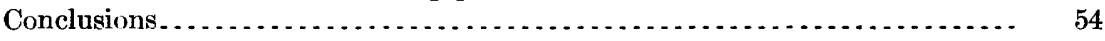

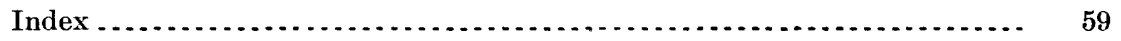




\section{L L U S TR A TI 0 NS.}

Puge.

II. $A$, Method of finishing pipe; $B$, Pipe with disks set ready for test.. 16

III. Details of disk and central rod ......................... 18

IV. $A$, Pipe under test; $B$, Method of raising end of pipe.......... 20

FIg. 1. Diagrammatic section of pipe, showing directions of tamping ....... 16

2. Sections of pipe, showing methods of connection .............. 47

3. Elevation of end of small pipes, with cover, used for determining permeability of different mixtures of concrete................ 50

4. Horizontal section of small pipes used for determining permeability

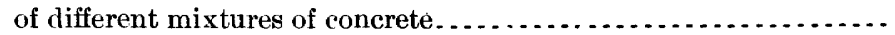





\title{
LETTER OF TRANSMITTAL.
}

\author{
DepartMent OF THE INTERIOR, \\ United States Geological Surver, \\ Hydrographic Branch, \\ Washington, D. C., March 25, 1905.
}

SIR: I transmit herewith a manuscript by John H. Quinton, supervising engineer of the Reclamation Service, entitled "Experiments on Steel-Concrete Pipes on a Working Scale," and request that it be published as one of the series of Water-Supply and Irrigation Papers.

The use of concrete as a substitute for stone and metal in connection with engineering projects has, during the last few years, become well-nigh universal. One of the most important fields of engineering investigation is that of determining the durability and permanence of concrete structures, especially those erected in connection with water supplies. The investigations reported in the accompanying manuscript are therefore of peculiar significance, and the results promise to be of great value.

Mr. Quinton's experiments have been made upon large pipes, and the results are therefore applicable for use in practical engineering work. Heretofore similar investigations have been made on a small scale, and the conclusions which have been drawn from them are, as shown in the accompanying paper, erroneous in many respects.

Very respectfully,

Hon. Charles D. Walcott,

F. H. Neweld, Chief Engineer.

Director United States Geological Survey. 



\section{EXPERIMENTS ON STEEL-CONCRETE PIPES ON A WORKING SCALE.}

By John H. Quinton.

\section{INTRODUCTION.}

Preliminary surveys of many irrigation projects in the arid States have shown that pressure pipes or, as they are often called, "inverted siphons," will be necessary for the economical construction of some of the works contemplated by the Reclamation Service. Hitherto such pipes have been made of iron or steel, or of wood staves bound with iron or steel rods. During the last few years the manufacture of . steel has been so improved that steel has entirely replaced iron in all important structures. Therefore the choice of material for pressure pipe has been limited to the two materials, steel and wood.

In all of the reclamation projects it is most important that the structures on the main canals shall be of a permanent nature. The works have to be maintained for several years by the Reclamation Service before they are turned over to the people of the district. They are to be paid for in ten annual installments, and at the end of ten years they should be in good repair and as sound and durable as when they were constructed. This condition is a difficult one to fulfill.

\section{STEEL PIPE.}

Steel pipe is naturally limited to a thin shell on account of its great strength, weight, and cost. It is easily attacked by salts and acids, both on the inside by the water flowing through it and on the outside by the material surrounding it. A slight deterioration in so thin a shell means a large loss in strength, and the life of a steel pipe is therefore limited to a few years, depending upon the nature of the material in which it is laid. Experience has shown that in alkali ground in southern California the life of sheet-steel pipe is short. The life of the pipe may be lengthened by a coating, both inside and outside, of asphaltic material. The coating is applied by dipping the pipe into a hot bath of the asphalt mixture. If this dipping is not carefully done at just the proper temperature it is not likely to add 
much to the life of the pipe. The coating is liable to be broken in places by careless handling in transit from the factory to the work, and unless such places are recoated they are soon attacked, and the efficiency of the pipe is thus materially lessened. In all of the projects in the arid States more or less alkali ground is encountered, and in many of the projects provision has to be made for the drainage of the lands to get rid of the alkali. Under these circumstances other and more durable material than steel or iron must be sought.

\section{WOODEN PIPE.}

Wooden pipes are now very extensively used for carrying water under pressure, and they have many advantages over steel. Large wooden pipes, however, must viecessarily be made of longitudinal staves, bound and held in place by steel rods on the outside. The wood is porous and is soon filled with the water under pressure, and this makes the wooden part of the pipe practically safe from decay when it is protected from the rays of the sun either by a layer of earth or a light roof. The pipe must be filled with water at all times, however, to maintain the condition of saturation which is necessary for its durability. In a cold climate, such as that found in Montana, Wyoming, and the Dakotas, it would be unwise to keep a pipe full of water in the winter time when it is not in use for irrigation. Freezing weather would certainly affect the pipe injuriously unless it were buried in the ground deep enough to be unaffected by frost. The entire bursting strength of a large wooden pipe is derived from the steel bands or rods with which it is bound, and these, when buried underground, are then exposed to the same destructive agencies which attack the steel pipe. The form of the bands, however, being generally circu'ar in section, gives them a longer lease of life than the thin shell of metal in a steel pipe; for this reason a wooden pipe is certainly a great improvement on a steel pipe.

Wooden pipes also have their limitations. They are fragile and easily broken by a blow from the outside and should never be used where they may be exposed to falling rocks or small landslides. If they are laid on the surface and exposed to the rays of the sun, the wood in the upper half of the pipe soon decays from alternate wetness and dryness, caused by different temperatures in sunshine and shade. In the heat of the sun the upper part of the pipe is dried rapidly, and during the night the pressure and capillary action force the water to the surface, to be dried out again the next day. This action may be counteracted in warm elimates by building a roof over the pipes, but in cold climates the pipe must be emptied before frost sets in and allowed to remain empty all winter. This, again, subjects the pipe to alternate wetness and dryness, although at longer intervals; it also allows the staves to shrink in the winter time, and when the water is 
turned into the pipe, and before the wood has had time to swell, sand and grit are forced into the seams between the staves, and the pipe becomes leaky and unserviceable.

In view of all these conditions, it was thought advisable to examine into the merits of steel concrete as a material for pressure pipes in the place of steel or wood.

\section{STEEL-CONCRETE PIPE.}

There is little doubt that steel concrete is a much more durable material than either steel or wood, but at the very outset it presents a serious drawback. Concrete is porous; and while theoretically it might be composed of such material as would render it impervious to water under ordinary pressures, practically it is found to be very difficult to make it so.

Many statements have been made as to the waterproof qualities of certain mixtures for concrete, but water under pressure is a very searching agent, and it must be admitted that so far as these experiments have gone such statements have not been substantiated. To determine just how much pressure of water ordinary well-made concrete would stand without leaking seriously, and what mortars would most effectually stop leaking, and up to what pressure, these experiments were undertaken.

It was recognized that experiments with small pipes would not be of such practical value as those with pipes of sizes more nearly commensurate with the work in hand. It was finally decided to make seven or eight pipes, each 5 feet in diameter inside and 20 feet long, with a 6 -inch thickness of concrete shell, inclosing an armor of steel rods sufficient to resist a bead of 150 feet of water with a factor of safety of 4 . The quantities of water to be carried in the different projects vary from 250 to 1,500 second-feet, and this size seemed as small as it would be advisable to experiment with in order to show the practical difficulties of construction, as well as the flaws and imperfections in the pipe arising from careless or defective workmanship.

Water under pressure tells the truth without fear or favor, and a careful reading of these pages will show that there are many practical difficulties to be overcome in the construction of steel-concrete pipe, and that the most careful attention to detalls and rigid inspection and supervision are necessary to produce a steel-concrete pipe that will stand 100 feet of head of water without appreciable leakage.

\section{COMPOSITION AND CONSTRUCTION OF PIPES.}

Experience with concrete structures has shown that with nearly all kinds of cement there is an efflorescence deposited on the surface of the concrete wherever there is sufficient water back of the wall to force this efflorescence to the surface. This is due to the permeability of 
the concrete and the passage of the water through it. Small particles of lime or cement are carried to the surface and deposited in the form of white powder.

There is also found in concrete a pulpy, gelatinous fluid, called by the French "laitance," from its milky appearance. Whenever water is forced through concrete this substance is deposited freely on the surface.

The entire subject of porosity and permeability of mortar and concrete has been very ably treated by M. R. Feret, chief of the Boulogne laboratory of the Ponts et Chaussées, in a paper published in the Annales des Ponts et Chaussées, July, 1892, and a most interesting discussion of the subject by American engineers is to be found in the Proceedings of the American Society of Civil Engineers, vol. 29, No. 6 . In this discussion Mr. R. W. Lesley suggested that an addition of slaked lime to the concrete of which the pipe is composed might aid in making the mortar impermeable. Some of the pipes tested have been made with this addition. Mr. Lesley also referred to a paper by Messrs. J. B. McIntyre and A. L. True on The Permeability of Concrete under High Water Pressures. Some of the conclusions drawn from the experiments made by these gentlemen are, however, rather sweeping.

In the second paragraph of these conclusions it is stated that concretes composed of mixtures of cement, sand, and rock in the proportions of $1: 2 \frac{1}{2}: 4$ were impermeable under heads varying from 20 to 80 pounds per square inch, and in the last paragraph the following statement is made:

It is perfectly safe to conclude that a concrete of the proportions of any of the specimens which did not leak under 80 pounds pressure would be practically impermeable under any condition ordinarily found in practice.

This seems a rather hasty conclusion, as the following pages show that many of the conditions ordinarily found in practice render it almost impossible to make a long and large conerete pipe impermeable. It is far from the intention of the writer to belittle in any way laboratory experiments, but great care must be exercised in drawing conclusions, especially in generalizing from particulars.

To determine just how a steel-concrete pipe, made by ordinary workmen in the usual practical way, would act under pressure was one of the main objects of these experiments.

It was decided to make seven pipes, with different proportions of sand, gravel, cement, lime, and waterproof material, with steel armor sufficient to resist a head of 150 feet of water, with a factor of safety of 4 , under such conditions as would be found in most of the projects under consideration by the Reclamation Service, these conditions being well understood by the writer, who had visited the various localities and was familiar with them. It was not intended or supposed that 
the experiments would cover a range great enough to exhaust the subject of impermeable concrete or mortar, but it was presumed that they would indicate the best mixtures and the limit of pressure whieh it would be wise to fix for actual work in the field, where pipes may be 3,000 or 4,000 feet in length and of large diameter.

\section{COMPOSITION OF TEST PIPES.}

The composition and dimensions of the test pipes are given below. All measurements were made loose, in boxes, just as they would probably be made in the field. These pipes were all made by workmen skilled in making concrete, who had been employed by a concrete contractor in Los Angeles. The work was supervised by the writer and by Mr. W. H. Sanders, consulting engineer of the Reclamation Service, one of whom was present at all times during the construction of the pipes.

Pipe No. 1.

Inside diameter, 5 feet; length, 20 feet; thickness, 6 inches; steel armor, 71 welded rings of three-fourths-inch round steel, and eight longitudinal steel rods one-half inch in diameter. In all pipes except No. 7 the armor was placed in the center of the shell.

Material used for concrete for pipe No. 1.

Parts.

Cement, Gillingham........................... 1

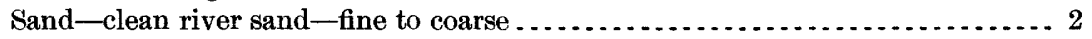

Gravel refused on screen of $1 \frac{1}{4}$-inch mesh and passing through $2 \frac{1}{2}$-inch mesh ... 2.5

Gravel refused on screen of half-inch mesh and passing through $1 \frac{1}{4}$-inch mesh.... 2.5

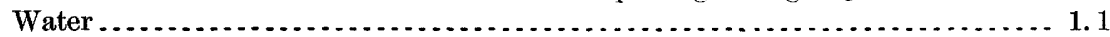

In this pipe 169 cubic feet of concrete in place required 214 cubic feet of solid materials, measured loose, or 243.2 cubic feet of solids and liquid. This pipe required 0.88 barrel of cement to one cubic yard of concrete.

Pipe No. 2.

Dimensions and armor same as No. 1.

Material used for concrete for pipe No. 2 .

Parts.

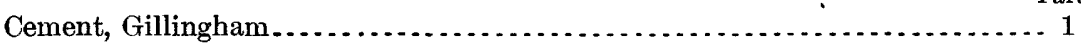

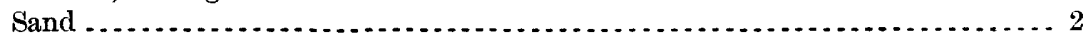

Gravel refused on 1-inch mesh and passing through $2 \frac{1}{2}$-inch mesh $\ldots \ldots \ldots \ldots \ldots$. 1.6

Gravel refused on half-inch mesh and passing through 1-inch mesh .......... 1.6

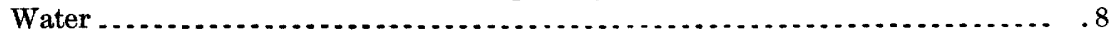

In this pipe 169 cubic feet of concrete required 243.75 cubic feet of solid materials, measured loose. This pipe required 1.27 barrels of cement to 1 cubic yard of concrete.

\section{Pipe No. 3.}

Dimensions and armor. same as No. 1. Half of the water used in the construction of this pipe was mixed with soap in proportion of 
one-half pound of soap to 1 gallon of water, and the other half was mixed with 1 pound of alum to 4 gallons of water. The materials are in the following proportions:

Material used for concrete for pipe No. 3.

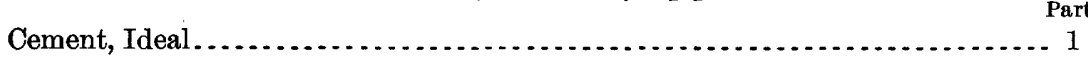

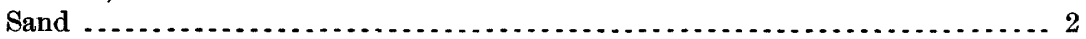

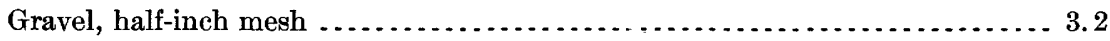

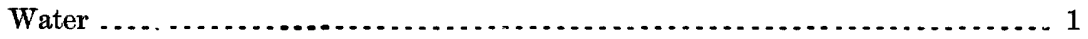

In this pipe 169 cubic feet of concrete in place required 234 cubic feet of solid materials, measured loose, or 272 cubic feet of solids and liquid. This pipe required 1.6 barrels of cement to 1 cubic yard of concrete in place.

\section{Pipe No. 4.}

Dimensions and armor same as No. 1.

Material used for concrete for pipe No. 4 .

Cement, Ideal

Sand

Gravel, all half-inch mesh.

Water

In this pipe it required 247 cubic feet of solids, measured loose, or 281 cubic feet of solids and liquid to make 169 cubic feet of concrete in place. This pipe required $1 . t$ barrels of cement to 1 cubic yard of concrete in place.

\section{Pipe No. 5.}

Dimensions and armor same as No. 1.

Material used for concrete for pipe No. 5 .

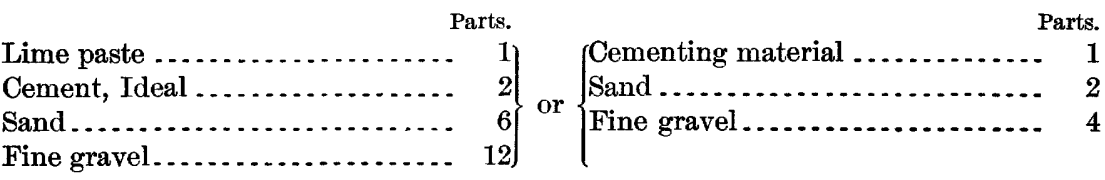

This pipe required 223 cubic feet of solids and paste, measured loose, to make 169 cubic feet of concrete in place. The amount of water used was not measured. This pipe required 0.84 barrel of cement and 81 pounds of lime paste to 1 cubic yard of concrete in place.

\section{Pipe No. 6.}

Dimensions and armor same as No. 1.

Material used for concrete for pipe No. 6 .

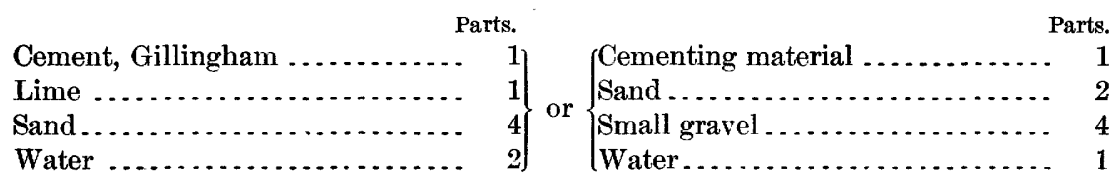




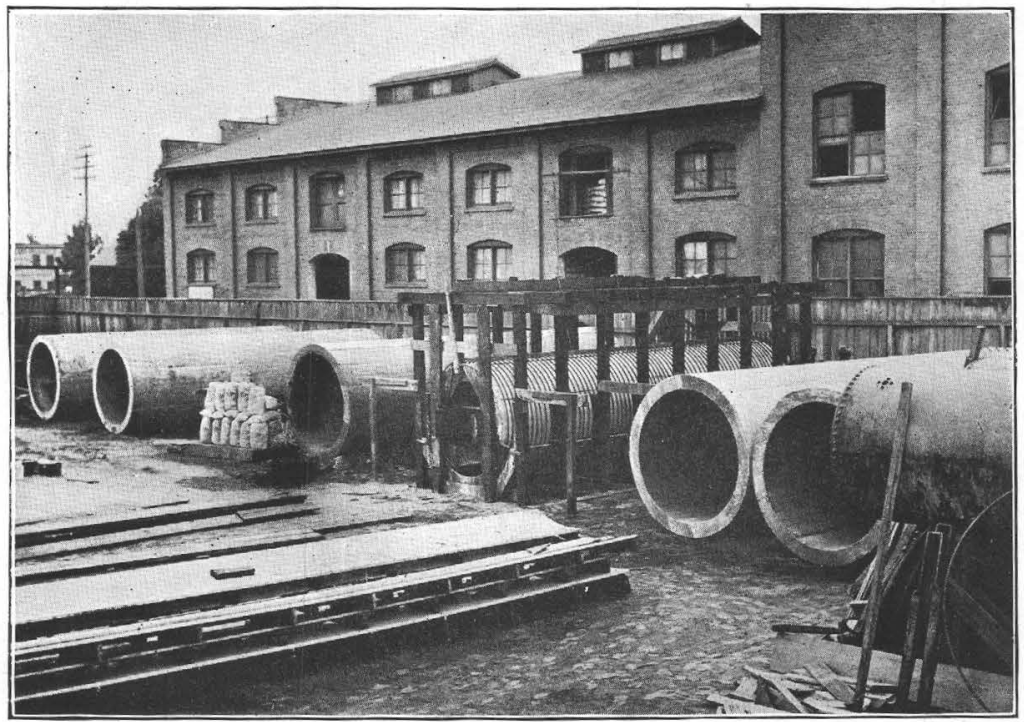

$A$

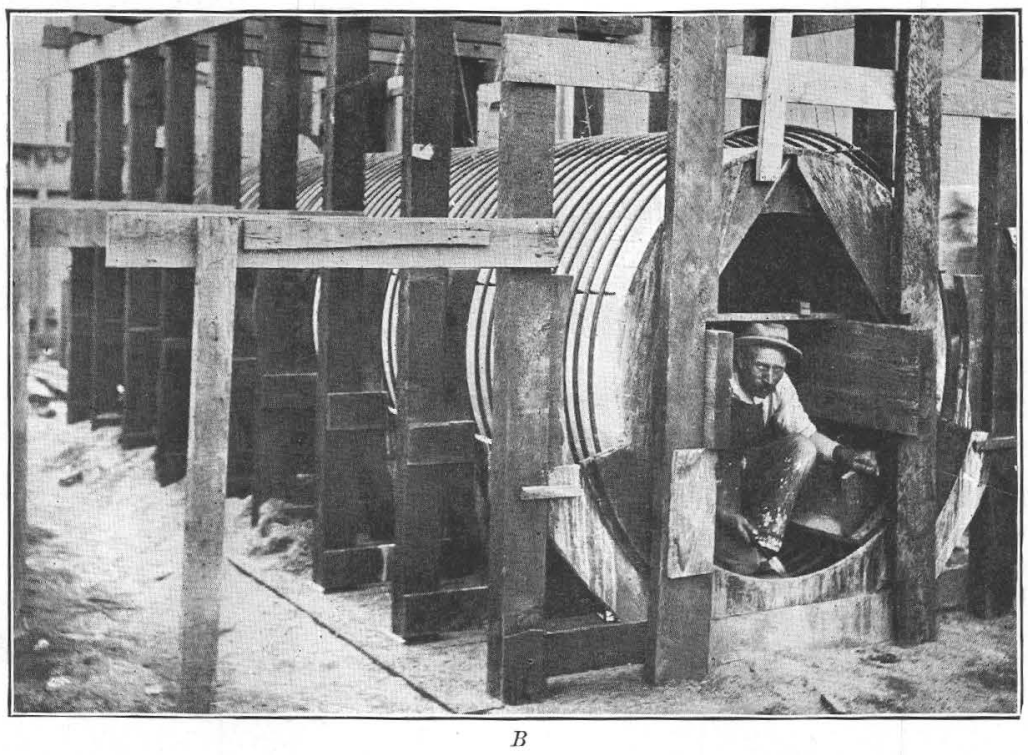

METHOD OF PIPE CONSTRUCTION. 
This pipe required 252 cubic feet of solids, measured loose, and 288 cubic feet of solids and liquid to make 169 cubic feet of conerete in place. It had 0.63 barrel of cement and 128 pounds of lime to 1 cubic yard of concrete in place.

Pipe No. 7.

Inside diameter, 5 feet; thickness of shell, 6 inches; length, 20 feet; steel armor composed of 41 pieces of half-inch, round, welded steel rod, held in place by 8 steel rods one-half inch in diameter and 20 feet in length. This armor is set $1 \frac{3}{4}$ inches from inside of shell.

Material used for concrete for pipe No. $\%$.

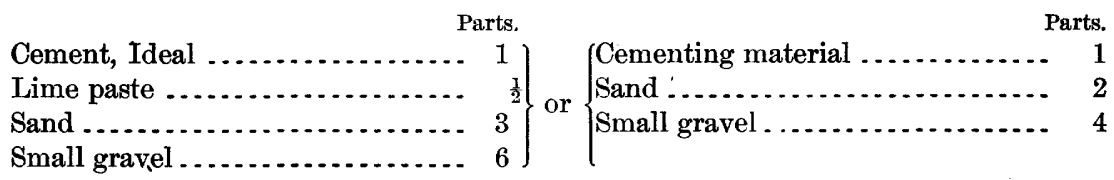

This pipe required 262 cubic feet of solids and paste to make 172 cubic feet of concrete in place. It was made with the intention of testing the elastic limit of the steel and concrete together as compared with the elastic limit of the steel alone, but it will be seen from a perusal of the experiments that this was impracticable on account of the leakage.

\section{METHOD OF PIPE CONSTRUCTION.}

The method of construction shown in Pl. I may be briefly described as follows:

Nine rectangular frames of 4 - by 6 -inch rough pine lumber are first set up on the line of the pipe, about $2 \frac{1}{2}$ feet from center to center. These frames are about 7 feet in width inside and 8 feet in height.

The sills of these frames are cut out to the form of the lower seventh of the outside surface of the pipe, and are sunk into the ground until the upper ends of the arcs are even with the surface of the ground. The frames are then steadied and braced in their true line, and the material of the ground surface is removed to the form of the lower part of the outside surface of the pipe, as indicated by the buried sills.

Tarred paper is now laid over this surface to prevent undue absorption of moisture from the cement by the earth or by dry material.

A long sill is then laid on top of the frames on center line, as shown in Pl. I, $A$, and from this the steel armor is suspended and held in place by a few small blocks, which are removed as the concrete work reaches them. The wooden form for the inside surface of the pipe is now placed inside the pipe in four sections and nailed together with intersecting chord pieces to form the upper six-sevenths of the 5-foot circle. This form is then supported inside, in its true position, by two pieces of 2 - by 12 -inch plank the full length of the pipe and extending 
beyond it at the ends. These planks are supported on two vertical pieces of 2 - by 8 -inch timber notched and held in place by spiking to the end frames.

This arrangement is exhibited in Pl. I, $B$, which shows the inside form and steel armor all ready for commencing the concrete work.

The first batch of concrete is laid on the tarred paper on the surface of the ground. This concrete has to be carried in buckets, and deposited quickly, and tamped through and under the steel armor for the full length of the pipe. Special tampers are made to fit between the rings and care is taken to keep the rings in their proper position until they are thoroughly covered with concrete. A wooden templet of the shape of the inside of the pipe is fixed at each end to guide the workmen in shaping the inside surface of the lower one-seventh of the

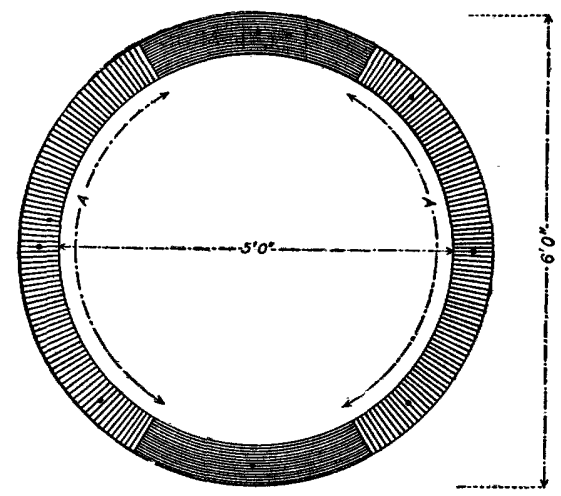

FIG. 1.-Diagrammatic section of pipe, showing directions of tamping.

pipe. This templet is plainly seen in front of Pl. I, $B$; the workman's trowel is pointing directly to it. The two lower sections of the outside form are also in place, so that as soon as the inside seventh of the pipe is completed the concrete can be run in and tamped from the outside and the work of laying it can be carried on continuously until the pipe is completed.

When the concrete has reached the top of these sections, another section of the outside form is added on each side, and so on until the upper part of the pipe ts reached, where there is no longer any necessity for an outside form. The sections of the outside form are seen piled up in the foreground of PI. I, $A$, and the method of fastening them to the outside frames is shown clearly in Pl. I, $B$.

The lower seventh of the pipe is tamped from the inside of the pipe in the direction of the pressure, and the upper eighth of the pipe is tamped from the outside in a direction opposite to that of the pressure. The remainder of the pipe (marked A, A, in fig. 1) is tamped in a direction normal to that of the pressure, or in what may be called a "circumferential direction." 


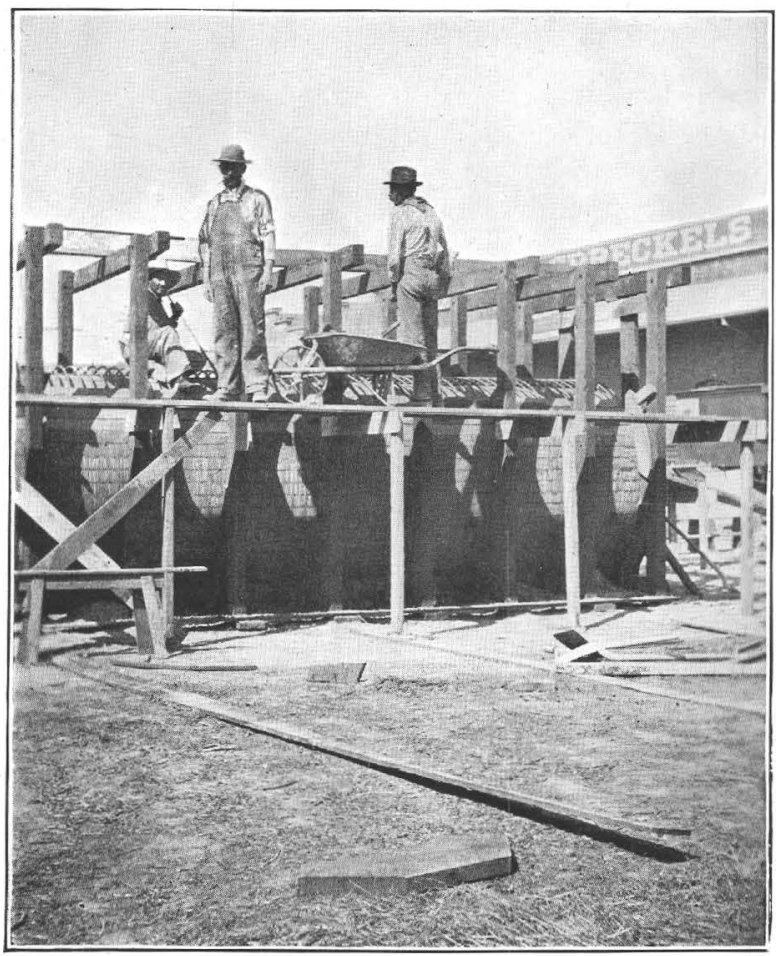

A. METHOD OF FINISHING PIPE.

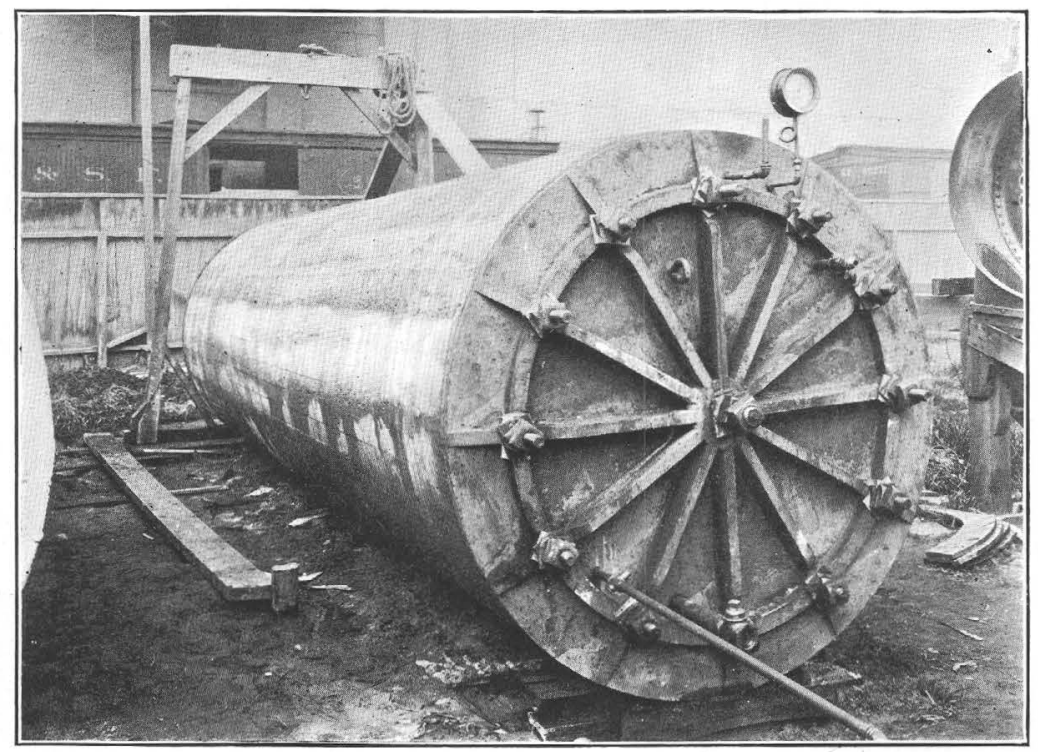

B. PIPE WITH DISKS SET READY FOR TEST, 
The experiments show a marked difference in the degree of perme ability of the concrete when tamped in these different directions.

All of the pipes were made on the same spot, as shown' by framework in Pl. I, $A$, and when hard enough were rolled over to left and right alternately, to give room for the construction of the next pipe.

Each pipe was kept wet, both inside and outside, for at least one week after completion, and the last three pipes were, in addition, covered with canvas to protect them from the rays of the sun.

The concrete was all mixed by hand in the following way:

In the case of sand, cement, and gravel, the sand and cement, after loose measurement in boxes, was first shoveled over three times dry; the gravel was then added and the entire mass turned over twice dry and three times wet, the last time with a hoe. It was then shoveled into buckets and wheelbarrows and laid in the pipe, where it was thoroughly tamped. The buckets were used for the lower seventh of the pipe; the wheelbarrows were used for the sides and top of the pipe.

PJ. II, $A$, shows method of finishing upper part of pipe.

In the case of sand, cement, gravel, and lime paste (pipe No. 5) the paste was measured in boxes in the same way as the other materials, and the mass mixed just as before; but in the case of pipes Nos. 6 and 7 the lime paste was mixed with the water, and the lime water was used for wetting down the concrete during the process of mixing.

The work was all done in a careful and painstaking manner, as nearly as possible in the way in which it would be done on any ordinary piece of work in the field, under careful supervision and inspection. The first pipe of this series was completed on August 29, 1903, and the last pipe, No. 7 , was completed on October 17, 1903. In the meantime all of the finished pipes were kept well wet, both inside and outside, so that they were thoroughly seasoned when the tests were commenced.

The pipes were all carefully squared up, and true planes were made at the ends with mortar composed of one part cement to one part sand, with a small quantity of lime paste to retard setting. This was done to make as perfect a joint as possible between the cast-iron ends used in testing and the pipe itself.

\section{APPARATUS USED FOR TESTING PIPES.}

To fill the pipes with water and make the ends tight under pressure two cast-iron disks, with suitable reenforcing ribs, were made and held in place by steel rods passing through the pipe and both disks. The inside faces of these disks were perfectly smooth, plane surfaces, as shown on Pl. III.

To, prevent leakage between the disk and the end of the pipe a ring of round rubber tire, $1 \frac{1}{4}$ inches in diameter, was placed between the disk

IRR $143-05-2$ 
and the shell of the pipe, and when the rods were tightened by the nuts at each end this gasket was flattened on the end of the pipe and formed a most effectual and tight joint under low pressures. It was found, however, that under high pressures the gasket was stretched at the joint, which was not vulcanized, and forced toward the outside of the pipe and caused leakage. To remedy this a ring of $\frac{1}{2}$ - by 1 -inch bar steel was placed around the gasket and between the disk and the end of the pipe, and no further trouble arose here.

In Pl. II, $B$, one of the disks is clearly shown on the end of pipe No. 2. The pipe is all ready for testing. The small pipe to the left of the gage is designed to allow air to escape when the pipe is being filled, each pipe being raised at one end so that the air can be expelled before pressure is applied.

The connection to the right of and below the gage is for filling the pipe from the city water pipe in the yard. The pipe in the lower left-hand corner is connected with a pump for raising pressure above city water pressures. The large connection in the lowest part of the disk is for emptying the pipe. The eye in the upper part of the disk, to the left of the center, is for the purpose of holding the disk when the rods are being adjusted. Each disk weighs about 1,500 pounds, and was raised to its place by a differential pulley hung from the light frame shown at the farther end of the pipe.

The disk at the farther end of the pipe is exactly similar and symmetrical with the one shown, but has no pipe connections, as they are not needed.

Pl. IV, A, shows another pipe under test with pump and hose complete.

Pl. IV, $B$, shows the method of raising the pipes at one end after they had been rolled to one side.

Each pipe weighed about 10 tons, and had to be raised with jackscrews and a sling of manila rope, as it was found impracticable to raise it by wedging, the material of the pipe being easily injured at the ends, where it was needed in perfect condition to allow a tight joint between disk and pipe.

\section{TESTS.}

The pipes lay in a position nearly east and west, the east ends being shown in the front of all photographs.

\section{PIPE NO. I.}

\section{PLASTER LININGS.}

On October 19, 1903, this pipe was covered on the inside with onehalf inch of plaster. Four plasters were used, the section covered by each plaster being 5 feet in length. 


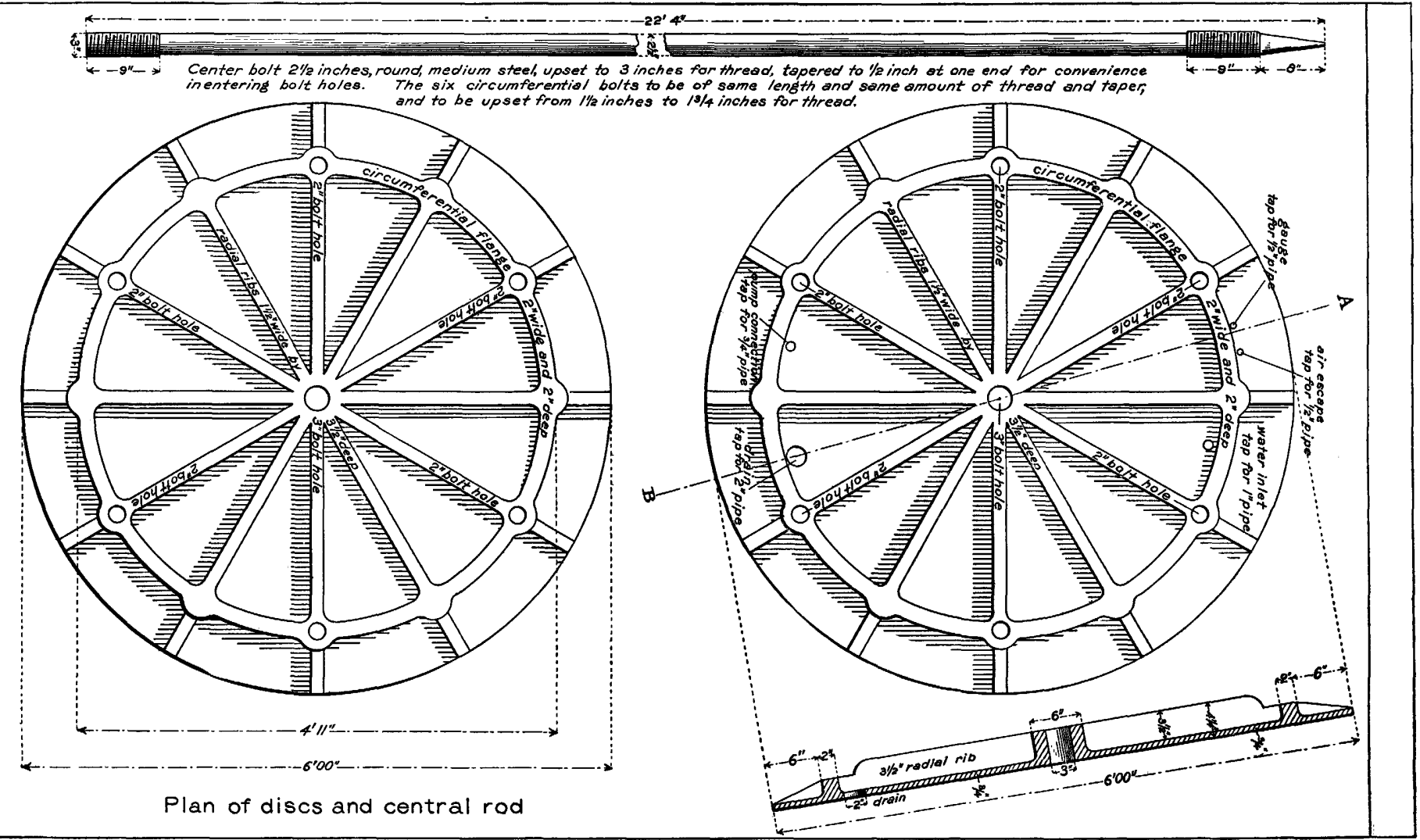

DETAILS OF DISK AND CENTRAL ROD. 
Plaster No. 1 was composed of 1 part cement to 1 part fine sand.

Plaster No. 2 was composed of 1 part cement and 1 part fine sand, mixed with alum and soap mixture-alum, 1 per cent by weight of cement and sand; soap, 1 per cent by weight of water.

Plaster No. 3 was composed of 1 part lime, 2 parts cement, and 6 parts sand.

Plaster No. 4 was composed of $\frac{1}{4}$ part lime, 1 part cement, and $3 \frac{3}{4}$ parts fine sand.

The plasters were kept well wet for several days after completion, and the test of the pipe was not made until February 26, 1904 .

Pipe No. 1, Test 1.

The results of the first test of pipe No. 1 are shown in the following table:

Test 1 of pipe No. 1.

\begin{tabular}{|c|c|c|c|}
\hline Date. & Hour. & Pressure. & Observations. \\
\hline \multirow[t]{8}{*}{ Feb. 26} & 9.08 a. m. & $\begin{array}{l}\text { Pounds. } \\
\quad 0\end{array}$ & Water turned into pipe. \\
\hline & $\begin{array}{l}12.58 \text { p. m. } \\
12.60 \text { p. m. }\end{array}$ & $\begin{array}{r}0 \\
15\end{array}$ & $\begin{array}{l}\text { Pipe full. } \\
\text { Leakage began. Especially strong along a longi- } \\
\text { tudinal seam, hereinafter designated as a "tamp- } \\
\text { ing seam," caused by necessary delay in adjustment } \\
\text { of form. }\end{array}$ \\
\hline & Later. & 23 & $\begin{array}{l}\text { Gage stationary; inflow counterbalanced by leakage. } \\
\text { South side (most exposed to sun) is porous and } \\
\text { leaks badly. No leakage from top section, which } \\
\text { was tamped without form. }\end{array}$ \\
\hline & 1.30 p. m. & 20 & \\
\hline & 3.00 p. m. & & Leakage on north side decreased fully 20 per cent. \\
\hline & 3.20 p. m. & 24.5 & \\
\hline & 4.45 p. m. & 25.5 & Decrease of 75 per cent in entire leakage. \\
\hline & 5.00 p. m. & & $\begin{array}{l}\text { No leakage in top section. Pressure turned off for } \\
\text { night. }\end{array}$ \\
\hline \multirow[t]{3}{*}{ Feb. 27} & 8.00 a. m. & 25 & Only 20 per cent of initial leakage persists. \\
\hline & 2.00 p. m. & & $\begin{array}{l}\text { Top section shows little moisture only. North side, } \\
\text { leakage almost ceased. South side, leakage de- } \\
\text { creasing; laitance appearing. }\end{array}$ \\
\hline & & & Pressure continued all night. \\
\hline \multirow[t]{3}{*}{ Feb. 28} & 11.30 p. m. & 15 & Gasket blown out causing small leak. \\
\hline & & & Pipe leaking on south side only. \\
\hline & & & Pressure continued all night. \\
\hline \multirow[t]{2}{*}{ Feb. $29^{\circ}$} & & 14.5 & $\begin{array}{l}\text { Not leaking appreciably except at gasket. Laitance } \\
\text { oozed out, nearly stopping holes in pipe. }\end{array}$ \\
\hline & 9.00 a. $\mathrm{m}$. & & Pipe emptied to repair gasket. \\
\hline
\end{tabular}


Of the four plasters applied to the inside of the pipe, as described on page 19, it was found that No. 4 allowed the smallest amount of leakage, while Nos. 1, 2, and 3, in order, rank next in effectiveness.

When pipe No. 1 was being constructed the sections next to the top on both sides were made of dry mixture, by order of Mr. W. H. San ders, as the watery cement was oozing from the boards at the bottom. It is remarkable that these two sections of 18 inches each show greater leakage and more gravel uncovered with mortar at the outside surface of pipe than the other sections. The other layers were put in very wet and the boards of the forms were coated with a layer of almost pure cement.

When the water was drained off and the disks were removed, an examination of the inside of the pipe revealed a hair crack the full length of the pipe on the south side, at the junction of the last section with the top section. This crack crossed all the mortars and was evidently due to a slight yielding of the concrete before the strain could be taken up by the steel armor.

This pipe was made with gravel of different sizes, with the idea that it might be less porous than a pipe with gravel of a more uniform size. It must be admitted, however, that the filling up of the interstices of the coarser material by the finer, which appears so plausible in theory, is most difficult to accomplish in practice.

The crack developed in the pipe shows that some lining or plaster of an elastic as well as of an impermeable nature must be found before these pipes can be placed under much pressure. A great many of the experiments have this end in view.

No arrangements had been made up to this time to measure the amount of the leakage from the pipes. It is evident that although a pipe might eventually dry up to such an extent under pressure as to reduce the leakage to an inappreciable amount, it might leak sufficiently before drying up to endanger its foundation, and cause the destruction of the pipe piecemeal. This would depend to some extent upon local conditions and the nature of the material on which the pipe rested. It will be seen from this experiment that the leakage is very much reduced by time, but it is doubtful whether this fact could often be used to advantage in practice, for the above-mentioned reasons.

The practically constant pressure of the city main was found to be much more advantageous for working on these pipes than the pressure developed by pumping. A quantity of laitance appeared on the outside surface of all pipes a few hours after they were put under pressure, and more or less matter composed of lime particles was con- 
U. S. GEOLOGICAL SURVEY

WATER-SUPPLY PAPER NO, 143 PL, IV

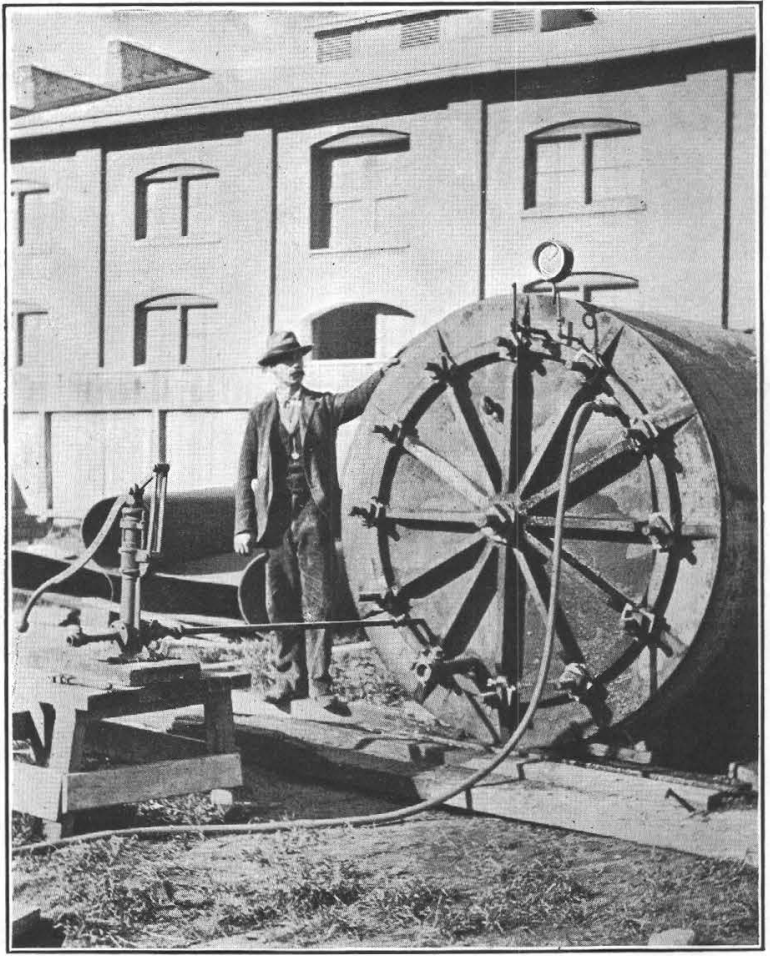

A. PIPE UNDER TEST.

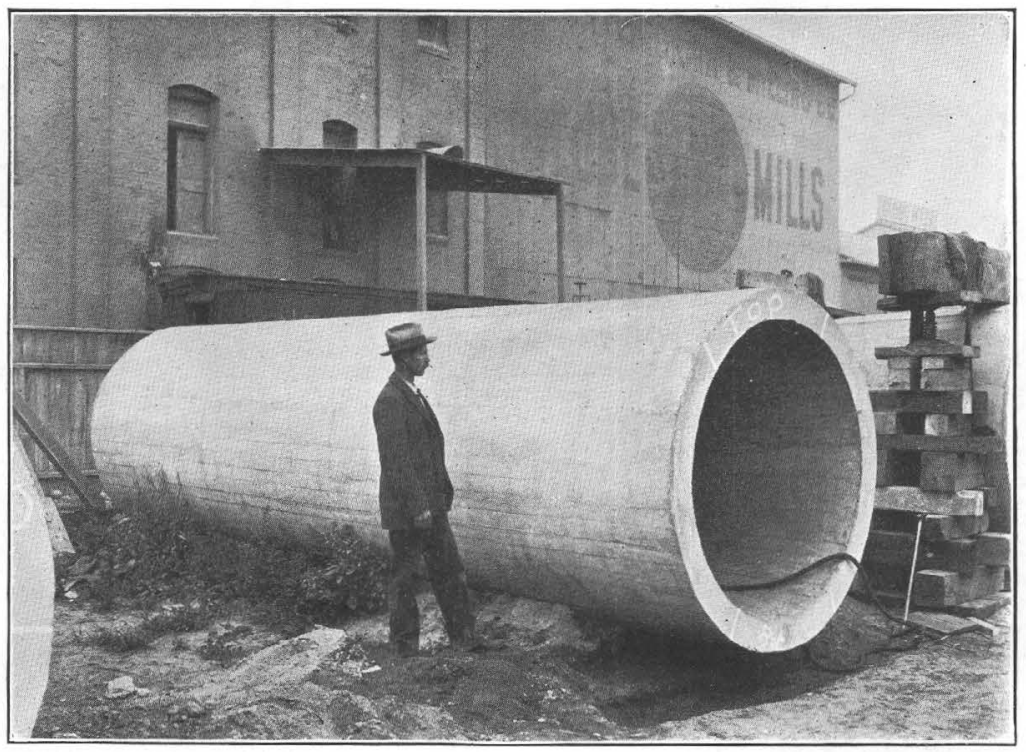

B. METHOD OF RAISING END OF PIPE. 
stantly exuding from them. Experience has shown that this material gradually fills up the pores and renders the pipe more impervious. A high pressure applied suddenly, as in pumping, would tend to force this matter rapidly through the pores and a great deal of it would be lost; whereas a slow, steady pressure would naturally permit a greater deposit. As a matter of fact few of the pipes or mortars were sufficiently impermeable to call for the aid of the pump in testing, as the city pressure varied between 37 and 42 pounds to the square inch, and this was as much as most of the pipes would stand without leaking so much as to endanger their foundations.

Pipe No. 1, Test 2.

As stated above (p. 18), this pipe was coated inside with four plasters in 5-foot sections. It received an additional coating of two coats of P. \& B. waterproof paint on the east half and two coats of Sylvester wash on the west half. On March 11, 1904, at $7.45 \mathrm{a}$. m., city water was turned on and gage immediately rose to 35 pounds. Leakage became free for the south side of the pipe, and was about twice as much as on the north side, while the portions covered by the P. \& B. paint did not leak one-half as much as those covered by the Sylvester wash. This was very evident on top, which, in the section covered by P. \& B. paint, showed barely a trace of moisture, but seven-eighths of the surface of the section covered by plaster No. 4 was moist. This was the plaster which showed the slowest percolation under test No. 1.

At $9 \mathrm{a} . \mathrm{m}$. the gage registered 36 pounds and the leakage was $2 \frac{3}{4}$ gallons per minute.

At 10 a. $\mathrm{m}$. gage registered 37 pounds. Leakage about the same.

At $3 \mathrm{p} . \mathrm{m}$. the pressure was reduced to 30 pounds and the leakage amounted to $2 \frac{1}{4}$ gallons per minute.

PIPE NO. 2.

PLASTER LININGS.

This pipe was covered on the inside October 20,1903 , with a halfinch coat of two different plasters, the section covered by each plaster being 10 feet in length.

Plaster No. 1 at the east end was composed of 1 part cement and 3 parts sand, loose measurement.

Plaster No. 2 at the west end was composed of 1 part cement, onehalf part lime, and $4 \frac{1}{2}$ parts sand, loose measurement. 
Pipe No. 2, Test 1.

The results of the first test of pipe No. 2 are as follows:

Test 1 of pipe No. 2.

\begin{tabular}{|c|c|c|c|c|}
\hline \multicolumn{2}{|c|}{ Date. } & Hour. & Pressure. & Observations. \\
\hline & & & Pounds. & \\
\hline \multirow[t]{15}{*}{ Mar. } & 1 & $9.00 \mathrm{a} . \mathrm{m}$. & 0 & Water turned into pipe. \\
\hline & & 11.30 a. m. & 0 & $\begin{array}{l}\text { Leakage from } 2 \text { pin holes, north side, one-third } \\
\text { way up. }\end{array}$ \\
\hline & & 11.45 a. $\mathrm{m}$. & 0 & $\begin{array}{l}\text { Leakage from } 3 \text { more pin holes on south side, east } \\
\text { section, along line of "tamping seam." }\end{array}$ \\
\hline & & $12.00 \mathrm{~m}$. & 0 & $\begin{array}{l}\text { Leakage from } 5 \text { more pin holes on south side at a } \\
\text { "tamping seam;" } 4 \text { in east section, one in west } \\
\text { section. }\end{array}$ \\
\hline & & 1.30 p. m. & $\ldots$ & Pipe full and pressure developed. \\
\hline & & 1.31 p. m. & 13 & Strong leakage commenced. \\
\hline & & 1.32 p. m. & 25 & Gage stationary, leakage counterbalances inflow. \\
\hline & & 2.00 p. m. & 25 & $\begin{array}{l}\text { Leakage on south (sunny) side twice as great as } \\
\text { on north. Practically no leakage on top section. }\end{array}$ \\
\hline & & 2.45 p. m. & 29 & Leakage decreased generally. \\
\hline & & 4.00 p. m. & 31 & Leakage still decreasing. \\
\hline & & 4.15 p. m. & 31 & \\
\hline & & 4.30 p. m. & 31.5 & Laitance and lime particles exuding freely. \\
\hline & & 5.00 p. m. & 31.75 & Leakage water shows lime. \\
\hline & & 8.05 p. m. & 35 & $\begin{array}{l}\text { Entire top section sweating freely. Lime forming } \\
\text { rapidly where leakage is greatest. }\end{array}$ \\
\hline & & $8.25 \mathrm{p} . \mathrm{m}$. & 35 & Pressure continued all night. \\
\hline Mar. & 2 & 7.40 a. m. & ... & Gasket on west end blown out. Pipe empty. \\
\hline
\end{tabular}

The city pressure in the mains is greatest early in the morning, when the draft on the reservoir is least and the inflow has raised the water to its maximum level for that day. It is presumed that when this pressure came on the pipe the friction between the disk and the rubber was not great enough to hold the gasket in place and it blew out at the joint. As the pressure had remained for about 20 minutes at 35 pounds, it is presumed that the leakage had continued to decrease and the pressure to rise accordingly until this accident happened some time during the night. To prevent a recurrence of this trouble a welded steel ring of section one-half by 1 inch and large enough to fit around the gasket when under pressure was made for each end, and these were placed in position and the heads were screwed up a quarter of an inch tighter than before. 
Pipe No. 2, Test 2.

The results of the second test of pipe No. 2 are as follows:

Test 2 of pipe No. 2.

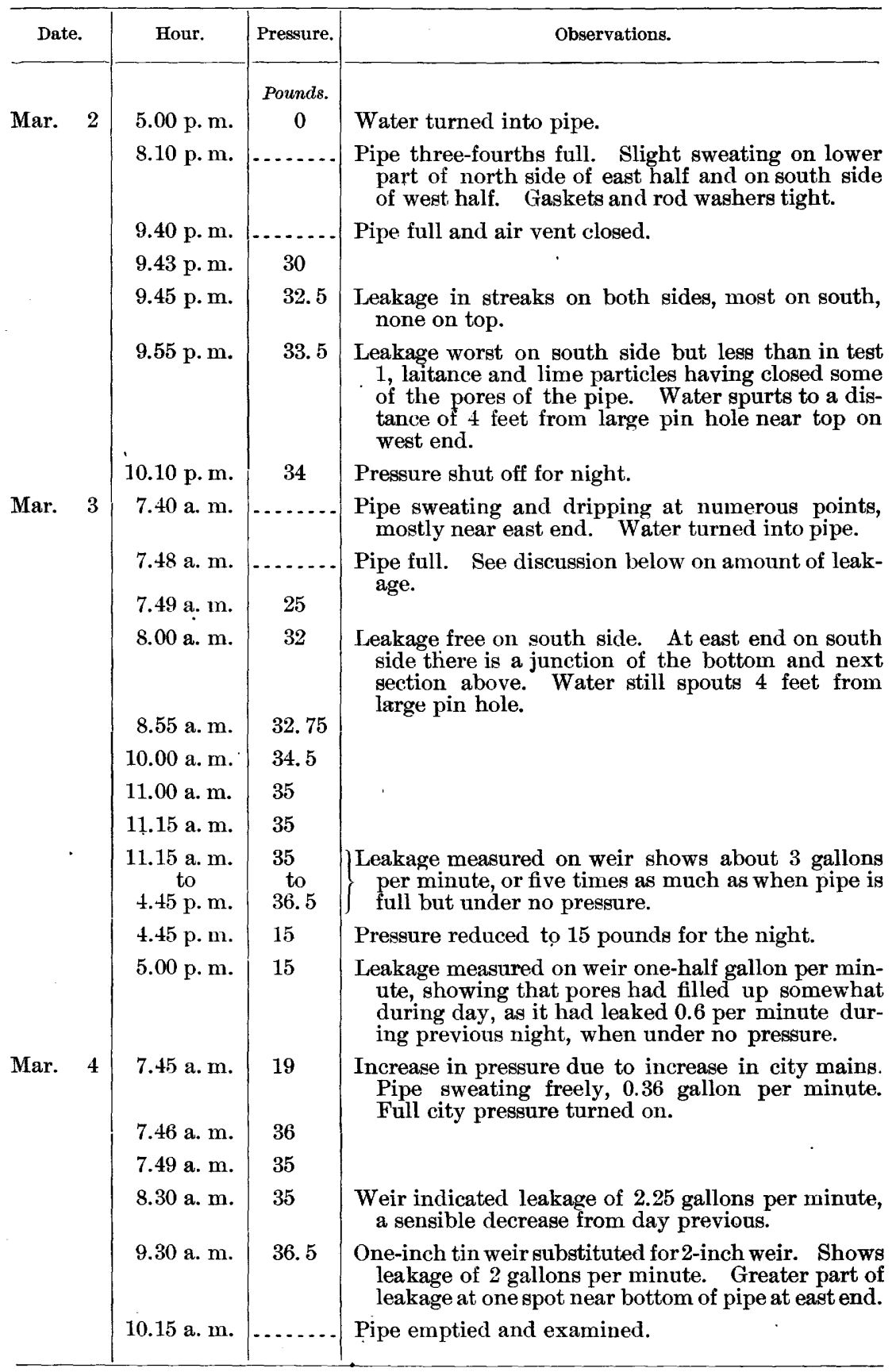


It will be noted from the above table that on March 3 at $7.40 \mathrm{a} . \mathrm{m}$. the water was turned into the pipe and in 8 minutes it was full, indicating that the pipe had leaked when not under pressure during the night a quantity equal to the run of the faucet for 8 minutes. Pipe No. 1 required 3 hours and 50 minutes to fill, and No. 2 required $4 \frac{1}{2}$ hours; the content of each pipe with heads screwed tight is about 395 cubic feet. Taking the mean time of filling the pipes as 250 minutes, the flow from the faucet would be 1.58 cubic feet per minute, and this multiplied by 8 equals 12.64 cubic feet, which represents the leakage during the night when no pressure was left on. This leakage, equivalent to $92 \frac{1}{2}$ gallons, occurred in $9 \frac{1}{2}$ hours of the night. This means a leakage from the pipe when not under pressure of 10 gallons an hour or 0.6 of a gallon per minute.

Provision was then made for measuring the leakage from the pipe when under pressure by making drains beneath it for collecting all the leakage water and leading it to a small tin weir 2 inches long.

The sand-cement plaster lining contained a perfect network of hair cracks, while the lime-cement plaster showed hardly any. The greatest leakage appeared to be in the east section of the pipe, which had been plastered with the sand-cement mixture.

Both sides of the pipe were thickly covered with laitance and lime deposits, but very little of either of these appeared on the top of the pipe.

\section{PIPE No. 2, Test 3.}

This pipe was originally treated with two kinds of cement mortar, and when tested the first time showed a leakage of 3 gallons per minute under a pressure of 37 pounds per square inch. It was then washed on the inside of the east half with two coats of pure cement wash, and on the west half with two coats of Sylvester wash.

Test 3 of pipe No. 2.

\begin{tabular}{|c|c|c|c|}
\hline Date. & Hour. & Pressure. & Observations. \\
\hline & & Pounds. & \\
\hline \multirow[t]{8}{*}{ Mar. 17} & \multirow[t]{3}{*}{ 7. 30 a. $\mathrm{m}$. } & 32 & No leakage below this pressure. \\
\hline & & \multirow[t]{2}{*}{35} & Leakage 1 gallon per minute. \\
\hline & & & $\begin{array}{l}\text { Top section of the pipe shows moisture only in spots } \\
\text { over about one-third of its area. }\end{array}$ \\
\hline & 9.00 a. $\mathrm{m}$. & $36 \frac{1}{2}$ & \multirow{5}{*}{$\begin{array}{l}\text { Leakage } 1 \text { gallon per minute. } \\
\text { Do. } \\
\text { Do. } \\
\text { Do. } \\
\text { Considerable laitance formed on upper half of pipe. } \\
\text { Leakage more of a general sweat and less flowing } \\
\text { streams. }\end{array}$} \\
\hline & 10.00 a. m. & 37 & \\
\hline & 1.00 p. m. & 39 & \\
\hline & 3.00 p. m. & 38 & \\
\hline & & & \\
\hline
\end{tabular}


Test 3 of pipe No. 2 -Continued.

\begin{tabular}{|c|c|c|c|}
\hline Date. & Hour. & Pressure. & Observations. \\
\hline Mar. 17 & 5.00 p. m. & $\begin{array}{r}\text { Pounds. } \\
38\end{array}$ & $\begin{array}{l}\text { Leakage about } 1 \text { gallon per minute. Full city pres- } \\
\text { sure left on all night. }\end{array}$ \\
\hline \multirow[t]{2}{*}{ Mar. 18} & 8.00 a. m. & 35 & $\begin{array}{l}\text { Leakage } 2 \frac{1}{2} \text { gallons per minute; caused probably by } \\
\text { opening of new pin holes or seams as result of } \\
\text { extra-heavy pressure on city mains developed } \\
\text { during the night. }\end{array}$ \\
\hline & 8.30 a. $\mathrm{m}$. & 0 & $\begin{array}{l}\text { Pipe allowed to remain full all day and during } \\
\text { night }\end{array}$ \\
\hline \multirow[t]{3}{*}{ Mar. 19} & 8.00 a. $\mathrm{m}$. & 22 & $\begin{array}{l}\text { Full city pressure turned on. No leakage, except at } \\
\text { one spot in bottom; apparently a serious imper- } \\
\text { fection in pipe. }\end{array}$ \\
\hline & 8.15 a. m. & 24 & Seepage on surface of pipe. \\
\hline & 9.00 a. m. & 35 & Sweat is more general, but not as much as on Mar. 17 . \\
\hline
\end{tabular}

Pipe No. 2, Test 4.

Pipe No. 2 received a coat of Richards plaster, which was placed over the plaster already on from test 2 , and a half sack of clay was deposited in the pipe before the heads were attached. On April 28, 1904 , this pipe was filled at 2 p. m. Pressure, however, was not applied till $2.30 \mathrm{p}$. m., so that Mr. Richards might be present at the test. There was absolutely no moisture visible on the outside of the pipe up to this time. This was not the case in previous tests. When the pressure was applied, the gage rose steadily until it reached 32 pounds and fluctuated between 32 and 34 pounds for half an hour before any leak was seen except near the bottom on the west end, where there was supposed to be a flaw in the pipe. In an hour there was a strong sweat at several places on the outside of the pipe, but not sufficient to allow any water to flow away. The weir showed a leakage of nearly 2 gallons per minute, nearly all of which came from the flaw. At $5 \mathrm{p}$. m. there was a trifle more sweat on the pipe, but the ground under and around the pipe remained dry, except at the west end, where the flaw was located. The pressure was now reduced and the pipe was left under a low pressure all night.

In the morning (April 29) the pipe was very sweaty under a pressure of 12 pounds, although there were several dry spots. The ground was somewhat moist in places, but was not soaked. The full pressure was now turned on, and the gage rose to 35 pounds. There was no visible leakage, the surface of the pipe drying off rapidly under the influence of the sun's rays. The water in the pipe was stirred up at intervals to keep the clay moving. The pipe remained under this pressure all day without any apparent change. The water which escaped through the flaw was colored with clay. 
The pump was applied in the afternoon and the pressure was raised to 40 pounds. The leakage through the flaw was so great, however, that it was determined to remove the heads and repair the flaw. This was done, and on May 2, 1904, the pipe was overhauled and a distinct crack was found in the plaster over the flaw in the pipe. The plaster was chipped off for about 2 feet square, and the imperfect part of the pipe itself was chiseled out to a depth of 2 inches. This was filled with good cement mortar and allowed to set thoroughly. In cutting into the crack or flaw it was found partly filled with clay.

On May 5 a coat of Richards plaster was placed on that part of the pipe that had been repaired, and on May 10 the pipe was filled at noon. As soon as the pressure was turned on the gage rose slowly to 39 pounds, and fluctuated between 38 and 40 pounds till $12.30 \mathrm{p}$. m., when moist spots began to show on the outside of the pipe, mostly on the south side.

At 1 p. m., the pressure remaining the same, the total amount of moist surface on the south side did not exceed 1 square yard, while the amount on the north side did not exceed $1 \frac{1}{2}$ square feet.

At $1.30 \mathrm{p}$. $\mathrm{m}$. the sweating had spread a little more, the pressure remaining the same. A little leakage around the gasket at the west end was probably caused by the plaster near the flaw not being thoroughly set. This leakage through the gasket amounted to a little less than one-tenth gallon per minute. The pump was now attached and the pressure was raised to 53 pounds, when the pipe commenced to sweat considerably. The pressure was kept up to this point for fifteen minutes, the sweating increased somewhat, and water began dripping in places along the south side.

At 2 p. m. the pressure was raised to 63 pounds and held there by pumping for two minutes. This developed a very strong sweat and a small leak near the top on the north side. The dripping increased to such an extent as to cause water to gather in the little drains at the sides of the pipe. The pressure was now lowered to 55 pounds and held there till $2.45 \mathrm{p}$. m., when the leakage amounted to half a gallon per minute, fully one-fifth of which came through the gasket. The pressure was maintained at from 53 to 56 pounds until $3.45 \mathrm{p}$. m., and the clay was kept in motion all the time, the weir showing an increase under this constant pressure.

At $4 \mathrm{p} . \mathrm{m}$. the pressure was allowed to fall to that of the city mains, and the gage registered 37 pounds.

At $4.30 \mathrm{p}$. m. the weir showed a leakage of one-tenth gallon only, which came entirely from one leak at gasket, the drip from the sweaty sides of the pipe not being sufficient to make the water flow to the weir. The pipe was left under pressure all night.

On May 11, at 8 a. m. the gage registered 38 pounds, the weir did 
not show any flow, and there was scarcely any drip from the sides of the pipe. The pipe was allowed to stand under city pressure and the clay stirred up occasionally until $3 \mathrm{p}$. m., when the pump was applied and the pressure raised to 55 pounds. At this pressure the weir showed a leakage of four-tenths of a gallon per minute. The pressure was then raised to 62 pounds and held there for a few minutes, and the leakage shown by the weir was three-fourths of a gallon per minute. When the pressure was reduced to 55 pounds the leakage fell to four-tenths of a gallon per minute.

The pipe remained under pressure all night, and at 8 a. m. on May 12 the gage read 39 pounds and there was no drip from the pipe. The surface on the outside of the pipe, however, was sweaty, but this moisture disappeared to a great extent under the influence of the sun. The pipe remained under city pressure all day (37-39 pounds) and the clay was kept, stirred up occasionally, but there was no apparent change in the condition of the pipe, so this experiment was concluded, and the heads were moved to No. 3. This was a very satisfactory test.

When this pipe was thoroughly washed inside to remove the clay, it was found that the plaster was still soft. This might account for the high pressure which this pipe stood, as a harder mortar might have cracked and caused greater leakage. A plaster which would remain soft and plastic for a long time might possibly afford a solution of the problem.

It will be observed that in these tests the amount of leakage varies considerably with the same pressure on different pipes. It was thought at first that the pressure and leakage should be proportional, but a little consideration will show that this could not be so.

It requires a greater pressure to force a given quantity of water through twelve small holes than it does to force the same quantity of water through one hole as large as all the small ones together, in the same time. If, therefore, the quantity of water which leaks through a pipe with only one opening is the same as that which passes through numerous small holes in another pipe in the same time, it is evident that the pressure on the pipe with small holes must be greater than that on the pipe with one large hole.

We may conclude then, that the pressure on a sweaty pipe will be greater than on a pipe with a few well-defined leaks, where the leakage is the same in both, in the same time, and that, with the same pressure, the leakage may vary with the number and character of the openings through which it takes place. This shows the great importance of careful workmanship on pipes of this kind. Unfortunately this class of work is most frequently done with unskilled labor, so that the practical difficulties in the way of producing a waterproof pipe, for a reasonable price, are thereby much increased. 
PIPE NO. 3.

Pipe No. 3, Test 1.

This pipe, as may be seen from its composition (p. 14), was made with the idea of testing a pipe constructed of waterproof material, and no coat of plaster was placed upon the inside.

Test 1 of Pipe No. 3.

\begin{tabular}{|c|c|c|c|c|}
\hline \multicolumn{2}{|c|}{ Date. } & Hour. & Pressure. & Observations. \\
\hline \multirow{4}{*}{\multicolumn{2}{|c|}{ Mar. }} & 400030 & $\begin{array}{c}\text { Pounds. } \\
\quad 0\end{array}$ & Water turned into nine \\
\hline & & 5.00 p.m. & 0 & $\begin{array}{l}\text { Leakage commenced on south construction side of } \\
\text { pipe; in general, much less leakage than in pipes } \\
\text { Nos. } 1,2 \text {, and } 4 \text {, as filling proceeds. }\end{array}$ \\
\hline & & 7.45 p.m. & 0 & $\begin{array}{l}\text { Leakages from pinholes in tamping seams at bot- } \\
\text { tom are more numerous than elsewhere. }\end{array}$ \\
\hline & & 9. 15 p.m. & 4 & $\begin{array}{l}\text { Pipe full and pressure turned on. Many pin holes } \\
\text { develop. Leakage exceeds } 9 \text { gallons per minute. } \\
\text { Pipe most impervious of any yet tested. Pres- } \\
\text { sure turned down for night. }\end{array}$ \\
\hline \multirow[t]{6}{*}{ Mar. } & 8 & $9.30 \mathrm{a.m}$. & 4 & Leakage 9 gallons per minute. \\
\hline & & $10.00 \mathrm{a.m}$. & 5 & Leakage about the same. \\
\hline & & 10.30 a.m. & $6 \frac{1}{2}$ & Leakage 8 gallons per minute. \\
\hline & & 10.45 a.m. & 7 & Do. \\
\hline & & 11.00 a.m. & 8 & Do. \\
\hline & & 4.00 p.m. & $11 \frac{1}{2}$ & Leakage 6 gallons per minute. \\
\hline
\end{tabular}

In the first test it was left in its rough state inside, just as it came from the forms, without any mortar, and the highest pressure that could be obtained on it was 12 pounds to the square inch, with a leakage of 5 gallons per minute. As the leakage was already sufficient to show that it would be unwise to build a pipe under such conditions in practice, it was determined to conclude this experiment, and the water was turned off and the pipe allowed to drain.

It was decided to give this pipe a coating of the different kinds of plaster and make another test on it, which is described below. It is very evident from the experiments that although the leakage decreases rapidly with time, some impermeable mixture in the shape of plaster must be applied to the inside of these pipes to prevent the immense leakage which would otherwise take place when the water is turned into the pipe. Such a plaster would allow a more gradual penetration of the material of the pipe by the water, and probably afford better conditions for filling the pores of the concrete with the compounds of lime which tend to close them, and render the concrete impervious. 
Pipe No. 3, Test 2.

The original composition of the pipe was 1 part cement, 2 parts sand, and 3.2 parts gravel (half-inch mesh), mixed with water impregnated with soap and alum.

The pipe now was coated inside on the east half with a mortar half an inch thick, composed of 1 part of lime paste, 1 part of iron filings, 2 parts of cement, and 6 parts of sand, all mixed with water having iron filings and sal ammoniac in the proportion of 70 pounds of iron filings and 12 ounces of sal ammoniac to 42 gallons of water. This mortar was first tried without lime, but it was found very difficult to make it adhere to the pipe. The lime was added to overcome the difficulty, and was quite successful for the purpose. The west half of this pipe was coated with half an inch of mortar, composed of 1 part of fine clay and 1 part of cement. This mortar checked badly in setting, but it was allowed to dry under the same conditions as the other mortar, the checks being permitted to remain as they developed, in order to determine how it would act under pressure. The iron mortar was finished on March 9, the clay mortar on March 10, and the pressure was turned on the pipe at $4 \mathrm{p}$. m. March 14 . The pressure ran up rapidly to 20 pounds per square inch without any leakage. Some small seams and pin holes then commenced to leak, and kept increasing until the pressure was up to 35 pounds, when the leakage amounted to $2 \frac{1}{2}$ gallons per minute. Three-fourths of this leakage was in the clay end of the pipe, and the iron mortar was evidently by far the more impermeable. From 4 to $5 \mathrm{p}$. $\mathrm{m}$. there was a very evident filling up of the leaky spots, all the pin-hole jets decreasing until they.were tiny leaks. The pressure was left on all night, and on the morning of March 15, at 8.30, the gage read 38 pounds, and the leakage was a little less than 1 gallon per minute.

With a pressure of 35 pounds the leakage through the iron mortar is not over one-tenth of that through the clay, and is so small as to be of no consequence in practice. The result of this experiment shows that with a pipe of Sylvester wash composition, and a mortar of iron filings, sal ammoniac, cement, lime, and sand, a head of 80 feet would be possible. Just how the sal ammoniac would act on the steel armor embedded in concrete it is impossible to state, and the condition of the armor when the pipe was broken is noted on p. 58 .

One peculiar circumstance connected with this pipe was that although the pressure in the morning was 38 pounds with a leakage of less than a gallon per minute, when the pressure was down to 35 pounds, owing, it is supposed, to the variations in the quantity of water drawn from the city pipes, water commenced to spurt in high jets from the pin holes, which had shown very little leakage at 38 pounds. These jets were all in the clay portion of the pipe. A possible explanation of this peculiar action is that the pin holes had been stopped up by small, 
loose particles of clay on the inside surface of the mortar. As soon as the pressure was relieved by a sudden draft on the city water pipes these particles may have been so far removed to one side of the pin hole as to allow the water to spout again. The pump was turned on to this pipe at $9 \mathrm{a}$. m., and the pressure forced up to 42 pounds. This started a few small jets through the iron mortar and increased those already found in the clay mortar to such an extent as would prevent the use of that part of the pipe under that pressure in practice. . When the heads were removed it was found that the mortars had cracked for the full length of the pipe in four different places at tamping seams, and all of the pin-hole leaks through the iron mortar were traced to these seams.

It was noticeable in this test that considerably more laitance appeared on the surface of the pipe at the east end than on that of the west end, although the leakage was very much less on the former section.

Thirty-eight pounds seems to be about the limit of pressure for this pipe and mortar. This is equivalent to a head of 87 feet, but considering the many imperfections of work in actual practice, it would not be safe to count on over 70 feet of head on such a pipe, and then only after the most rigid inspection and supervision of the construction of the pipe.

It is evident from this experiment that as soon as the pressure is sufficient to stretch the steel beyond the tensile strength of the concrete the yielding of the concrete will allow the weakest seam to open.

When pumping, the pressure tending to burst the pipe was, for 1 inch in length of pipe,

$$
\pm 2 \times 30 \text { (radius in inches) }=1,260 \text { pounds, }
$$

and the area of section of concrete resisting this pressure was 6 square inches, so that the actual strain on the concrete alone amounted to $\frac{1260}{6}=210$ pounds per square inch. The steel rods are three-fourths inch in diameter and are set $3 \frac{3}{8}$ inches from center to center, so that if the pressure is taken up by the steel alone it would amount to

$$
\frac{1260 \times 3 \frac{3}{8}}{0.44}=9,66 \pm \text { pounds per square inch, }
$$

and although this is below the elastic limit of the steel this strain would cause the steel to stretch enough to crack the concrete, which, of course, would yield first at the weakest place, probably a seam.

Practically, it is very difficult, if not impossible, to make concrete pipes of large diameter without seams, either longitudinal or transverse, and to overcome this defect it would be necessary to have an elastic as well as an impermeable quality in the plaster. Efforts will be made in future tests to find such a plaster for lining. 
Pipe No. 3, Test 3.

In the second test of this pipe, described above, two different kinds of mortar were used-iron mortar on the east half and clay mortar on west half. As the clay mortar did not give satisfactory results it was chiseled off and in its place was substituted a plaster composed of 1 part of Ideal cement, 1 part screened sand, and one-fourth part lime putty, all moistened with iron and sal ammoniac water. The east half was allowed to remain as it was in test No. 2 . The entire inside of pipe was coated with a wash of cement mixed with "iron" water.

Test 3 of pipe No. 3.

\begin{tabular}{|c|c|c|c|}
\hline Date. & Hour. & Pressure. & Observations. \\
\hline \multirow[t]{7}{*}{ Mar. 23} & \multirow[t]{2}{*}{2.55 p. m. } & $\begin{array}{l}\text { Pounds. } \\
25\end{array}$ & $\begin{array}{l}\text { Pressure turned on. Number of pin holes north } \\
\text { side near top spouting. }\end{array}$ \\
\hline & & 30 & Few small leaks on south side near top. \\
\hline & 3.30 p. m. & 35 & $\begin{array}{l}\text { Leakage strong along two of the cracks which were } \\
\text { visible on inside of the pipe after second test. }\end{array}$ \\
\hline & 4.00 p. m. & 39.25 & $\begin{array}{l}\text { Leakage } 1.75 \text { gallons per minute. Leakage on south } \\
\text { side diminished. No pin holes spouting. North } \\
\text { side, } 9 \text { or } 10 \text { pin holes spouting. Ninety per cent } \\
\text { of all leakage occurs here. }\end{array}$ \\
\hline & 4.30 p. m. & 39.25 & Same leakage as above. \\
\hline & 5.00 p. m. & 20 & $\begin{array}{l}\text { Pressure reduced for the night to allow cracks to } \\
\text { close up. Leakage } 0.75 \text { gallon per minute with } \\
\text { strong sweat at cracks and no pin holes. }\end{array}$ \\
\hline & 8.15 p. m. & 30 & $\begin{array}{l}\text { Leakage } 0.75 \text { gallon per minute. Strong sweat. } \\
\text { No pin holes. }\end{array}$ \\
\hline \multirow[t]{8}{*}{ Mar. 24} & 7.30 a. $\mathrm{m}$. & 36 & Leakage 0.25 gallon per minute. \\
\hline & 7.30 a. m. & 38 & $\begin{array}{l}\text { Full city pressure. No perceptible change in ap- } \\
\text { pearance of pipe. }\end{array}$ \\
\hline & 8.00 a. m. & 39.5 & Leakage 0.25 gallon per minute. \\
\hline & $9.00 \mathrm{a} . \mathrm{m}$ & 40 & $\begin{array}{l}\text { A few pin holes commenced to spout. Pressure then } \\
\text { turned down to } 32 \text { pounds, and spouting ceased. }\end{array}$ \\
\hline & & & $\begin{array}{l}\text { This pressure continued to ascertain if leaking seam } \\
\text { will close or cease to leak at higher pressure. }\end{array}$ \\
\hline & $12.00 \mathrm{~m}$. & 32 & $\begin{array}{l}\text { Pipe drying fast. Weir shows leakage less than } \\
0.1 \text { gallon per minute. }\end{array}$ \\
\hline & 2.00 p.m. & 32 & Pipe much dryer. \\
\hline & 4.30 p. m. & 35 & $\begin{array}{l}\text { Leakage so small as to be barely recorded. Pipe } \\
\text { dry over half this surface. }\end{array}$ \\
\hline \multirow[t]{4}{*}{ Mar. 25} & 7.30 a. $\mathrm{m}$. & 34 & $\begin{array}{l}\text { Only sweat in parts of crack. Weir shows no per- } \\
\text { ceptible leakage. Full city pressure turned on. }\end{array}$ \\
\hline & 7.45 a.m. & 40 & No strong leaks until 8.15 \\
\hline & \multirow[t]{2}{*}{8.15 a. m. } & 40 & $\begin{array}{l}\text { Leakage } 0.3 \text { gallon per minute. Pump started and } \\
\text { pressure raised to } 45 \text { pounds. All pin holes spout } \\
\text { freely. }\end{array}$ \\
\hline & & 48.5 & $\begin{array}{l}\text { Cracks leaked so much that pump can not overtake } \\
\text { leakage. }\end{array}$ \\
\hline
\end{tabular}


When the heads were removed from this pipe the two old cracks from test 5 were seen plainly developed in the plaster, although one did not run through the full length of the pipe. There were also three small new cracks visible. This was certainly the most satisfactory of all the tests so far. It must be borne in mind that a pipe in actual practice would not be subject to much fluctuation in pressure, and as long as the pipe did not leak materially under the pressure due to the maximum level of water in the canal, it would probably get more impermeable with age. The ends of the pipe being always open it could not be subjected to very severe water hammer if proper provision was made for removing air.

\section{Pipe No. 3, Test 4.}

When this test was made the pipe was in the same state as after the third test, except that the plaster was repaired. Before the heads were put on this pipe there was placed inside of it 100 pounds of clay and 2 pounds of wood ashes, the object of this test being to determine the efficiency of clay and ashes as a means of stopping leakage in a concrete pipe.

On April 19, 1904, at 3.45 p. m., this pipe was filled and the pressure rose to 25 pounds before any noticeable leak occurred. When the pressure reached 30 pounds leakage became greater, and water spouted very freely along the seams that had been chiseled out and filled with mortar on the inside. The clay and ashes were kept well stirred up inside and the water which came through the leaky places was very muddy. The pressure was gradually increased to 32 pounds; the leakage was $t_{2}^{\frac{1}{2}}$ gallons per minute. This pressure was kept on during the rest of the day, the clay being stirred constantly. At $5 \mathrm{p} . \mathrm{m}$. the pressure was reduced for the night. On April 20, 1904, at 8 a. m., full pressure was again turned on and clay stirred up. The pressure rose to 34 pounds and the leakage amounted to $33^{3}$ gallons per minute. By noon the pressure had increased to 35 pounds, but the clay seemed to blow through the cracks and the pipe was leaking so much that it was decided to discontinue the experiment.

\section{Pipe No. 3, Test 5.}

The pipe was thoroughly washed inside to remove all the clay which remained after test 4 . This left the pipe with one-half inch of two different kinds of plaster on the inside, as described in tests 3 and 4 .

On April 26 an additional plaster of 1 part of cement to $1 \frac{1}{2}$ parts of sand was applied and troweled down to a smooth surface. This plaster was kept well wet till seasoned, and on May 14 the pipe was filled, a sack of clay having first been deposited inside. 
Test 5 of Pipe No. 3.

\begin{tabular}{|c|c|c|c|c|}
\hline \multicolumn{2}{|c|}{ Date. } & \multirow{2}{*}{ Ilour. } & \multirow{2}{*}{$\begin{array}{r}\text { Pressure. } \\
\text { Pounds. } \\
32\end{array}$} & Observations. \\
\hline May & 14 & & & $\begin{array}{l}\text { Two large pin holes near top on east end of north } \\
\text { side; } 1 \text { small pin hole at west end. }\end{array}$ \\
\hline & & 11.00 a. m. & & $\begin{array}{l}\text { Strong sweat spots on north side. Small pin holes } \\
\text { stopped spouting. }\end{array}$ \\
\hline & & $12.00 \mathrm{~m}$ & 37 & $\begin{array}{l}\text { General sweat on pipe. Leakage } 0.75 \text { gallon per } \\
\text { minute. Clay stirred constantly, and pressure } \\
\text { allowed to remain all the afternoon, fluctuating } \\
\text { between } 35 \text { and } 40 \text { pounds. }\end{array}$ \\
\hline & & 5.00 p. m. & & $\begin{array}{l}\text { Weir indicates leakage of a iittle more than one-half } \\
\text { gallon per minute. }\end{array}$ \\
\hline \multirow[t]{2}{*}{ May } & 16 & 8.00 a. m. & 38 & $\begin{array}{l}\text { General sweat; } 2 \text { large pin holes, leaking freely. } \\
\text { Total leakage, one-half gallon per minute. }\end{array}$ \\
\hline & & 5.00 p. m. & 36 & Leakage about same as in the morning. \\
\hline \multirow[t]{7}{*}{ May } & 17 & 8.00 a. $\mathrm{m}$. & 39 & $\begin{array}{l}\text { Leakage } 0.4 \text { gallon per minute. Considerable lai- } \\
\text { tance has formed on outside of the pipe. As finger } \\
\text { is run along full length of pipe sweat seems to } \\
\text { break and does not show any flow except on north } \\
\text { side, where several leaks are found. At place of } \\
\text { leakage thick coat of iron oxide deposited on out- } \\
\text { side of pipe. Clay constantly stirred during fore- } \\
\text { noon. }\end{array}$ \\
\hline & & $12.00 \mathrm{~m}$. & 39 & Leakage 0.35 gallon per minute. \\
\hline & & 2.30 p. m. & 56 & $\begin{array}{l}\text { Pump attached. Pressure maintained for } 25 \text { min- } \\
\text { utes. Leakage of } 1 \text { gallon per minute. Leak- } \\
\text { age along upper seam on north side. Strong } \\
\text { sweat on south side }\end{array}$ \\
\hline & & 2.55 p. m. & 62 & $\begin{array}{l}\text { Pressure raised by fast pumping and held for } 12 \\
\text { minutes. Leakage } 2 \text { gallons per minute. Ten } \\
\text { per cent from bolt holes and gaskets. }\end{array}$ \\
\hline & & 3.00 p. in. & ... & $\begin{array}{l}\text { Pressure allowed to fall to that in city mains and } \\
\text { maintained there for remainder of dav. }\end{array}$ \\
\hline & & 3.30 p. m. & 36. & $\begin{array}{l}\text { Leakage } 0.75 \text { gallon per minute. This would indi- } \\
\text { cate that the pores of the pipe had been opened } \\
\text { by great pressure. }\end{array}$ \\
\hline & & 5.15 p. m. & 38 & $\begin{array}{l}\text { Slight reduction in leakage. Pipe is left under city } \\
\text {.pressure all night. }\end{array}$ \\
\hline \multirow[t]{2}{*}{ May } & 18 & 8.00 a. $\mathrm{m}$. & 39 & $\begin{array}{l}\text { Leakage } 0.5 \text { gallon per minute. Pores apparently } \\
\text { closing up. Pressure kept on all day; clay agitated. }\end{array}$ \\
\hline & & 5.00 p. m. & 38 & $\begin{array}{l}\text { Slightly reduced leakage. Pressure left on all } \\
\text { night. }\end{array}$ \\
\hline \multirow[t]{2}{*}{ May } & 19 & 8.00 a. $\mathrm{m}$. & 37 & $\begin{array}{l}\text { Leakage } 0.35 \text { gallon per minute. Pipe under city } \\
\text { pressure all day. }\end{array}$ \\
\hline & & 5.00 p. m. & 38 & $\begin{array}{l}\text { Leakage } 0.35 \text { gallon per minute. Pipe under pres- } \\
\text { sure all night. }\end{array}$ \\
\hline May & 20 & & 37 & $\begin{array}{l}\text { Leakage } 0.35 \text { gallon per minute. Considerable } \\
\text { laitance and lime on the surface. No leakage, } \\
\text { except at pin holes, where oxide of iron is get- } \\
\text { ting harder. Pipe under pressure all night and } \\
\text { all next day. }\end{array}$ \\
\hline
\end{tabular}

IRR $143-05-3$ 
Test 5 of Pipe No. 3-Continued.

\begin{tabular}{|c|c|c|c|c|}
\hline Date. & & Hour. & Pressure. & Observations. \\
\hline May & 20 & 5.00 p. m. & & $\begin{array}{l}\text { Pipe quite dry. Leakage } 0.3 \text { gallon per minute } \\
\text { Pipe left under pressure until May } 23 \text {, when pres- } \\
\text { sure was reduced to zero. }\end{array}$ \\
\hline May & 25 & & 38 & $\begin{array}{l}\text { Leakage } 0.25 \text { gallon per minute. Pipe left under } \\
\text { pressure for night. }\end{array}$ \\
\hline May & 26 & & 38 & $\begin{array}{l}\text { Leakage } 0.1 \text { gallon per minute. Pressure con- } \\
\text { tinued. }\end{array}$ \\
\hline May & $\because 7$ & $5.00 \mathrm{p.m}$. & $38-40$ & $\begin{array}{l}\text { Same leakage; pressure released at noon. } \\
\text { Pressure again applied and continued all night. }\end{array}$ \\
\hline May & 28 & & 39 & $\begin{array}{l}\text { Pipe quite dry. Leakage less than } 0.1 \text { gallon per } \\
\text { minute. Pressure continued. }\end{array}$ \\
\hline May & 29 & & 39 & $\begin{array}{l}\text { Conditions same as day previous. Pressure now } \\
\text { turned off. Pipe allowed to remain full of water } \\
\text { until June 2. }\end{array}$ \\
\hline June & 2 & & 60 & $\begin{array}{l}\text { Pressure raised by pumping. Increased for a short } \\
\text { time to } 65 \text { pounds, when new piu holes blew out } \\
\text { on south side. Pressure allowed to fall to } 38 \\
\text { pounds and allowed to remain there until June } 9 .\end{array}$ \\
\hline
\end{tabular}

This pipe was left under city pressure from 5 p. m., May 14, to 8 a. m., May 16. Many engineers and practical pipe makers assert that time is an important element in closing the pores of a cement pipe. This was considered an excellent opportunity for this test, as the workmen were employed in the yard making another pipe of the same diameter and thickness, but in sections of 5 feet each.

June 9, 1904, when the leakage had been reduced so that it could no longer be measured through a weir 1 inch wide, the only leaks visible on the surface were from the two pin holes on top, and the leaks from them had been very much reduced in the last few days. This pipe had now been practically under city pressure for about three weeks, and the leakage had decreased from three-fourths gallon per minute to less than one-tenth gallon per minute.

This reduction of leakage might be due to the filling up of the pores of the pipe in this case with clay, lime deposits, laitance, or oxide of iron, or partly with one or more of these substances.

The fact that oxide of iron formed rapidly on outside of the pipe only at the pin holes does not necessarily prove that the sal ammoniac might permeate the concrete and attack the steel rods, but naturally leads to grave suspicion that it does so. An examination of the steel: rods where the pipes are broken up will show what has happened:

Just what influence the clay may have had in this case it is difficult to say, but another experiment will show what clay can do on an unplastered concrete pipe. 
PIPE NO. 4.

Pipe No. 4, Test 1.

Pipe No. 4 was constructed September 12, 1903. No plastering was done on this pipe. During the time the experiments were being made on pipes Nos. 1 and 2, from February 26 to March 4, 1904, this pipe was coated inside on its east half with two coats of $P . \& B$. waterproof paint No. 1, and its west half with three coats of soap and alum mixture, commonly called "Sylvester wash." This was applied precisely as recommended in Trautwine's Pocket Book, p. 672. It was assumed from the results of experiments on pipes Nos. 1 and 2 that it would be useless to attempt a test of a pipe without some waterproof plaster or wash on the inside. The Sylvester wash being so much used for waterproofing was thought to be a good wash with which to make the first test, and as an elastic coating of some kind was deemed important the P. \& B. paint was selected.

Test 1 of pipe No. 4.

\begin{tabular}{|c|c|c|c|}
\hline Date. & Hour. & Pressure. & Observations. \\
\hline \multirow[t]{4}{*}{ Mar. 4} & 4.30 p. m. & $\begin{array}{c}\text { Pounds. } \\
0\end{array}$ & Water turned into pipe. \\
\hline & 5.00 p. m. & 0 & $\begin{array}{l}2 \text { small sweat spots on } \mathrm{P} . \& \mathrm{~B} \text {. section; strong drip } \\
\text { on Sylvester wash section. }\end{array}$ \\
\hline & 8.40 p. m. & 0 & $\begin{array}{l}\text { Pipe seven-eighths full. Only slight seepage in } \\
\text { lower half. }\end{array}$ \\
\hline & 9.25 p. m. & 0 & $\begin{array}{l}\text { Pipe full. Leaks develop freely in both sections. } \\
\text { Gage would not record; therefore removed for } \\
\text { repairs, and light pressure left on pipe all night. }\end{array}$ \\
\hline \multirow[t]{3}{*}{ Mar. 5} & $8.00 \mathrm{a} . \mathrm{m}$. & 7 & Leakage 9 gallons per minute. \\
\hline & 10.00 a. $\mathrm{m}$. & $8 \frac{1}{2}$ & Leakage decreasing. \\
\hline & 3.30 p. m. & $10 \frac{1}{2}$ & $\begin{array}{l}\text { Leakage decreasing, but still sufficiently bad to ren- } \\
\text { der pipe unsafe in practice. Water shut off and } \\
\text { pipe allowed to soak. }\end{array}$ \\
\hline Mar. & 8.00 a. m. & 0 & Water leaked out amounting to 26 gallons per hour. \\
\hline
\end{tabular}

The appearance of the pipe outside and the location and quantity of the leakage indicate that the Sylvester wash makes a better lining than the waterproof paint. On the Sylvester wash section of the pipe there were several streaks of absolutely dry concrete, whereas the P. \& B. section showed moisture on all the surface except the top, which, as the pipe had been reversed in position, was the bottom during construction.

The reason for so much leakage through a so-called "waterproof" paint was explained by an examination of the inside of the pipe. It 
was found that as the inside surface was rough, many indentations had simply been bridged over by the paint, and when pressure was applied these spots had yielded and allowed water to pass through.

The result of this test with the Sylvester wash is disappointing, and it is easy to conjecture what the leakage from the pipe would have been without the wash. The difference in leakage between the plastered pipes Nos. 1 and 2 , and No. 3, which was washed, would seem to favor the application of a good plaster to the inside of all concrete pipes subjected to the pressure of water.

It was remarked in the tests of the pipes Nos. 1 and 2 that the leakage on the south side of each of these was very much greater than that on the north side. These pipes, although rolled over from where they were made, stood in the same relative position as to top and bottom as that in which they were made. It was at first thought that the action of the sum on the south side of these pipes for the five months during which they had remained in the yard had affected that side injuriously, but when pipe No. 4 was being tested it was observed that the greatest leakage occurred on the north side. On examination of this pipe it was found that it stood in the reverse position from that in which it was made-that the bottom of the pipe now stood uppermost.

It is evident, then, that it was not the fact that the pipes had stood so long under the rays of the sun in the yard after being made that had affected the south side injuriously, because in pipe No. \pm the north side instead of the south side seemed to have been affected. As all the pipes were made on the same spot it is probable that it was the greater evaporation on the sunny side when the pipes were being made, especially at the tamping seam, that had affected them in this way, and all the experiments tended to corroborate this view of the matter. It would seem advisable, therefore, in making concrete pipes to hold water to insist upon their being made in the shade. As in the other pipes, the bottom of this pipe does not leak nearly as much as the sides, the moisture not being sufficient to cause any flow.

\section{Pipe No. 4, Test 2.}

As stated above, this pipe was coated on the inside with two coats of P. \& B. waterproof paint on east half and with two coats of Sylvester wash on the west half. The first test was completed on March 7, 1904 , and on March 28 this pipe was coated on the west end, over the. Sylvester wash, with a plaster made of 1 part boiled linseed oil, 2 parts coal tar, 1 part sand, and $1 \frac{1}{+}$ part cement; and on the east end over the P. \& B., with a wash composed of 1 part of boiled linseed oil and 2 parts coal tar, enough to make a good, thick paint. This was laid on with a brush. 
Test 2 of pipe No. 4.

\begin{tabular}{|c|c|c|c|c|}
\hline \multicolumn{2}{|l|}{ Date. } & Hour. & Pressure. & Observations. \\
\hline \multirow{8}{*}{\multicolumn{2}{|c|}{ Apr. }} & 8.00 a. m. & 0 & Water turned into pipe. \\
\hline & & 12.20 p. m. & & Pipe full; some sweat during filling process. \\
\hline & & & 10 & Pipe commenced to leak. \\
\hline & & & 16 & Leaked freely; less under plaster than under wash. \\
\hline & & 12.40 p. m. & 18 & Leakage 6 gallons a minute. \\
\hline & & 1.30 p. m. & 19 & Do. \\
\hline & & $2.30 \mathrm{p.} \mathrm{m}$. & 21 & $\begin{array}{l}\text { Slight decrease of leakage; pipe sweating over } \\
\text { whole surface; pressure now cut to } 4 \text { pounds. }\end{array}$ \\
\hline & & 4.30 p. m. & 5 & Pressure increased; leakage 2.75 gallons per minute. \\
\hline
\end{tabular}

It has been suggested by a great many engineers and practical men in the pipe business that fine clay or ashes, or both, deposited in the water passing through the pipe would eventually seal up all the leaks and make the pipe practically tight.

It was determined to test this theory, and accordingly a small stuffing box was placed on one of the cast-iron heads, and an agitator in the form of a small rake with a handle of half-inch round steel, working in the stuffing box, was added to the equipment, so that the clay was kept stirred up when the pipe was under pressure.

It was determined to make a close exanination of all the pipes tested up to this time, with a view to putting them in shape for testing some more theories of making steel-concrete pipe impermeable in actual practice. During the examination it was found that in order to make the pipes serviceable for further tests it would be necessary to chisel out the longitudinal cracks which had been developed in pipes Nos. 3 to 5, inclusive, and fill up these cracks with a strong mortar. The cracks were accordingly chiseled out about 1 inch deep. In doing this three important facts were disclosed.

(1) Pipe No. 5 was not a hard concrete. It seemed to be of a crumbly nature, and it would have been easy to cut a hole through it.

(2) Some of the longitudinal cracks in pipes Nos. 3 to 5 , inclusive, were found to be in radial planes through the longitudinal rods, but only at the rods which are placed on the sides of the pipe, in sections A, A, as shown in fig. 1, p. 16.

It is possible that in tamping, the longitudinal rods in sections $\mathbf{A}, \mathbf{A}$ may have sprung a little and exerted a tensile strain at these points in the material of the pipe, rendering them the weakest places when the additional pressure of the water was turned on.

(3) The concrete in No. 3 was exceedingly hard, and the plaster had become loose in the bottom part of the pipe, so that it was an easy 
matter to remove a strip 2 feet wide for the full length of the pipe. This strip was replaced with fresh mortar of the kind used on this pipe before.

\section{PIPE NO. 5 .}

Prpe No. 5, Test 1.

The west third of the pipe was covered on the inside with one coat of a wash made by Mr. C. E. Richards, of Los Angeles, who claims to have a waterproof wash and plaster for concrete or brick walls. The middle third had one coat of plaster and one coat of wash, and the east third of the pipe had two coats of plaster. This pipe was made September 22, 1903, and treated inside by Mr. Richards March 9 and 10, 1904. The wash was applied on March 9 and the mortar on March 10. The plaster has a very smooth and oily appearance. The process is not patented, but is a trade secret.

Test 1 of pipe No. 5.

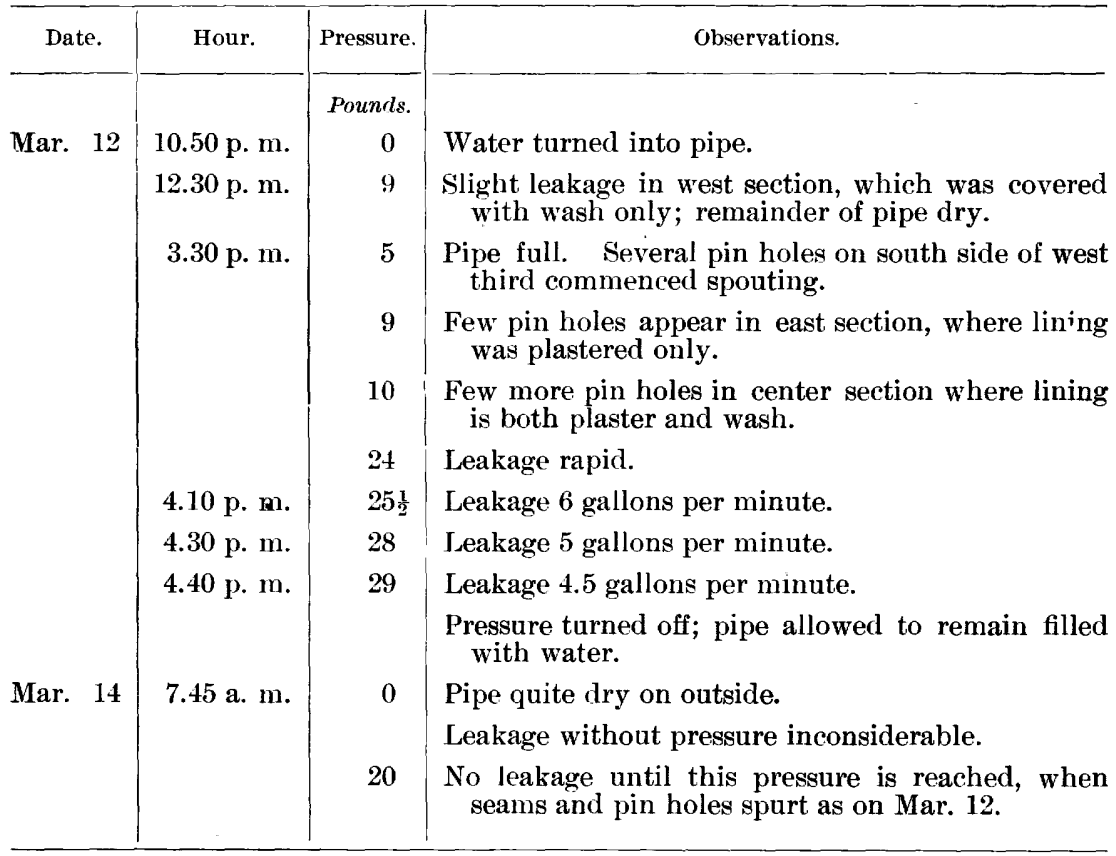

As this pipe had leaked so much in first half hour under pressure, the experiment was concluded.

Pipe No. 5, Test 2.

In the first test of this pipe it was coated on inside with Richards wash and plaster as follows: West third, one coat of wash. Middle third, one coat of plaster and one coat of wash. East third, two coats of plaster. 
On March 22, 1904, this pipe received on the east and middle thirds an additional coat of plaster. This plaster was composed of 1 part cement, 1 part screened sand, and one-fourth part lime putty moistened with iron water. When dry it was covered with a light wash of iron and cement. On March 23 the west third received a coat of Richards plaster.

Test 2 of pipe No. 5.

\begin{tabular}{|c|c|c|c|}
\hline Date. & Hour. & Pressure. & Observations. \\
\hline \multirow{4}{*}{ Mar. 29} & & $\begin{array}{c}\text { Pounds. } \\
18\end{array}$ & Leaks begin to show on outside. \\
\hline & \multirow{2}{*}{$4.15 \mathrm{p} . \mathrm{m}}$. & 20 & $\begin{array}{l}\text { Leaks quite iree. Numerous pin holes near the } \\
\text { top in "iron plaster" region of section, while } \\
\text { Richards plaster section remains dry. }\end{array}$ \\
\hline & & 25 & $\begin{array}{l}\text { Richards plaster section begins to show leakage, } \\
\text { though not as much as remainder of pipe. Total } \\
\text { leakage } 4 \frac{1}{2} \text { gallons per minute. }\end{array}$ \\
\hline & 4.40 p. m. & 28 & $\begin{array}{l}\text { Laakage same. Pressure reduced to } 12 \text { pounds for } \\
\text { night to prevent too much leakage. }\end{array}$ \\
\hline \multirow[t]{11}{*}{ Mar. 30} & 8.00 a. $\mathrm{m}$. & 23 & $\begin{array}{l}\text { Leakage } 1 \text { gallon per minute. Thirty per cent of } \\
\text { this leakage from cracks in the plasters on the } \\
\text { end of the pipe where pressure under gasket has } \\
\text { affected them. }\end{array}$ \\
\hline & 8.00 a. $\mathrm{m}$. & 30 & No perceptible increase in leakage. \\
\hline & & 34 & $\begin{array}{l}\text { Strong leakage at } 2 \text { spots on south sicle at junction } \\
\text { of } 2 \text { plasters. No pin holes. }\end{array}$ \\
\hline & 9.00 a. $\mathrm{m}$. & 36 & $\begin{array}{l}\text { Leakage } 3 \text { gallons per minute. Ditches running to } \\
\text { weir and submerged surface of weir sustained } \\
\text { heavy deposit of laitance. }\end{array}$ \\
\hline & 10.00 a. $\mathrm{m}$. & 36 & Leakage 3 gallons a minute. \\
\hline & 11.00 a. $\mathrm{m}$. & $36 \frac{1}{2}$ & Do. \\
\hline & $12.00 \mathrm{~m}$ & 37 & Do. \\
\hline & $2.00 \mathrm{p.} \mathrm{m}$. & $37 \frac{1}{2}$ & Leakage 2.75 gallons per minute. \\
\hline & 3.00 p. m. & 37 & Do. \\
\hline & 5.00 p. m. & 37 & Do. \\
\hline & & & Pressure reduced to 8 pounds for the night. \\
\hline \multirow[t]{3}{*}{ Mar. 31} & 8.00 a. $\mathrm{m}$. & 14 & $\begin{array}{l}\text { Leakage } \frac{3}{8} \text { gallon per minute. General sweat on } \\
\text { the pipe. Full city pressure turned on and gage } \\
\text { raised at once to } 35 \text { pounds. }\end{array}$ \\
\hline & 8.30 a. $\mathrm{m}$. & 36 & Leakage $2 \frac{1}{2}$ gallons per minute. \\
\hline & 9.00 a. m. & 36 & Same leakage. Force pump applied. \\
\hline
\end{tabular}

The pressure could not be raised above 39 pounds with the pump, although the pin holes did not spout. As the test was very satisfactory the pipe was emptied. It showed considerable laitance on the outside. and a slight tendency to close up, but leaked too much in the first 24 hours to make a safe pipe for practice. 


\section{Pipe No. 5, Test 3.}

This pipe was now coated inside with two coats of a tufa elastic paint, claimed by the proprietor to be an impermeable material. The first coat was applied July 27; second coat applied August 4.

The results of the third test of pipe No. 5 were as follows:

Test 3 of pipe No. 5.

\begin{tabular}{|c|c|c|c|}
\hline Date. & Hour. & Pressure. & Observations. \\
\hline \multirow[t]{4}{*}{ Aug. 10} & 11.45 a. $\mathrm{m}$. & Pounds. & $\begin{array}{l}\text { Water turned into pipe. When pipe was nearly } \\
\text { full small leak developed at west end. }\end{array}$ \\
\hline & 3.50 p. m. & & $\begin{array}{l}\text { Pipe filled; when air cock was closed pressure raised } \\
\text { nearly } 25 \text { pounds. Leakage appeared to be at } \\
\text { joint near top on south side; also along bottom. }\end{array}$ \\
\hline & & $\begin{array}{l}30 \\
\cdot\end{array}$ & $\begin{array}{l}\text { Leakage began on north side near top and along } \\
\text { bottom. Few leaks on sides and } 1 \text { pin hole. } \\
\text { Bottom leaked quite freely. }\end{array}$ \\
\hline & 4.30 p. m. & 34 & $\begin{array}{l}\text { General sweat all over pipe. Most leakage along two } \\
\text { seams in the bottom. }\end{array}$ \\
\hline \multirow[t]{4}{*}{ Aug. 11} & $5.00 \mathrm{p.m}$. & $\begin{array}{l}34 \\
30\end{array}$ & $\begin{array}{l}\text { Leakage same. Pressure maintained over night. } \\
\text { Leakage } 13 \text { gallons per minute. Only two places } \\
\text { where there was an appreciable flow except in } \\
\text { bottom where there was a strong drip. }\end{array}$ \\
\hline & & 32 & $\begin{array}{l}\text { Leakage } 2 \text { gallons per minute. No appreciable } \\
\text { change in appearance of pipe. }\end{array}$ \\
\hline & 11.00 a. $\mathrm{m}$. & 36 & Leakage 2.2 gallons per minute. \\
\hline & & & $\begin{array}{l}\text { Before this test was commenced three large cracks } \\
\text { were observed on the ontside of the pipe, two of } \\
\text { them being at the junctions of the top layer with } \\
\text { the sides, running the full length of the pipe. } \\
\text { The third crack extended one-half the length of } \\
\text { the pipe and was in the center of the top layer. } \\
\text { None of these cracks showed on the inside, nor } \\
\text { didl any of them leak under a pressure of } 34 \\
\text { pounds. }\end{array}$ \\
\hline
\end{tabular}

Thirty-six pounds pressure seems from the above tests to be a measure of the efficiency of the tufa elastic paint. The same pipe leaked $2 \frac{1}{2}$ gallons per minute in test 2 under a pressure of 36 pounds.

When the heads were removed from the pipe it was found that the paint was covered with blisters, ranging from one-eighth to threefourths of an inch in diameter. There were also many blotches of wrinkled surfaces. As the pipe dried out on the inside a number of surface checks developed, similar to those which occur when paint is put on any surface too thickly.

It must be admitted that all of these tests made on washes or paints gave very poor results; nor is this to be wondered at when it is con- 
sidered that a wash or coat of paint is generally so thin that water under pressure is sure to penetrate it sooner or later, unless it were in the nature of a glaze. A glaze, however, being generally put on with heat, is necessarily impracticable for pipes such as are required for use in the Reclamation Service.

PIPE NO. 6.

Pipe No. 6, Test 1.

This pipe was coated on the inside east half with a wash of pure cement (Ideal). No wash or coating on west half.

Test 1 of pipe No. 6.

\begin{tabular}{|c|c|c|c|}
\hline Date. & Hour. & Pressure. & Observations. \\
\hline Mar. & 2.15 p. m. & $\begin{array}{r}\text { Pounds. } \\
0\end{array}$ & Water turned into pipe. \\
\hline & 4.00 p. m. & 0 & $\begin{array}{l}\text { No leakage in washed section. Pronounced leak- } \\
\text { age in unwashed section, though not so much as } \\
\text { in previous tests at the same stage of filling. } \\
\text { Leaks mostly in "tamping seams." Pipe left for } \\
\text { the night with small quantity of water flowing in, } \\
\text { to soak it up gradually. }\end{array}$ \\
\hline Mar. 10 & 9.00 a. $\mathrm{m}$. & 0 & $\begin{array}{l}\text { Full head city pressure turned on Leakage at im- } \\
\text { perfect places in unwashed section greater than } \\
\text { supply from city main. Pipe emptied for com- } \\
\text { plete inside coating. }\end{array}$ \\
\hline
\end{tabular}

Pipe No. 6, Test 2.

The pipe leaked so badly during the first test in the unwashed portion that it was impossible to fill it with a hose delivering 11 gallons of water per minute. The west half was covered with two coats of Sylvester wash and cement mixed, and the east half was covered with an additional coat of pure cement wash, which, with the two coats applied in the first test, made three coats of pure cement wash on east half. These coats were applied March 10 and 11. At 8 o'elock on March 16, 1904, water pressure was turned on and the pipe leaked 6 or 7 gallons per minute under 17 pounds of pressure. The leaks were principally through seams, and as they showed no appearance of diminishing by noon the pipe was emptied and the heads were removed to No. 2 for a second test of that pipe. It is quite evident from this test that a wash alone on the inside of a steel concrete pipe is not so effective as a plaster. It is possible, however, that a wash on top of a plaster might be a good thing, and another test will have a bearing on this subject. 
Pipe No. 6, Test 3.

This pipe, when last tested, had on the inside three coats of pure cement wash on east half and two coats of cement mixed with Sylvester wash on west half, and the result of the test being unsatisfactory, on March 21, 1904, another coat of cement mixed to a thick paint with boiled linseed oil was applied, and on March 22 another coat thicker than the first. The two coats required 40 pounds of cement and $3 \frac{1}{4}$ gallons of oil.

Test 3 of pipe No. 6.

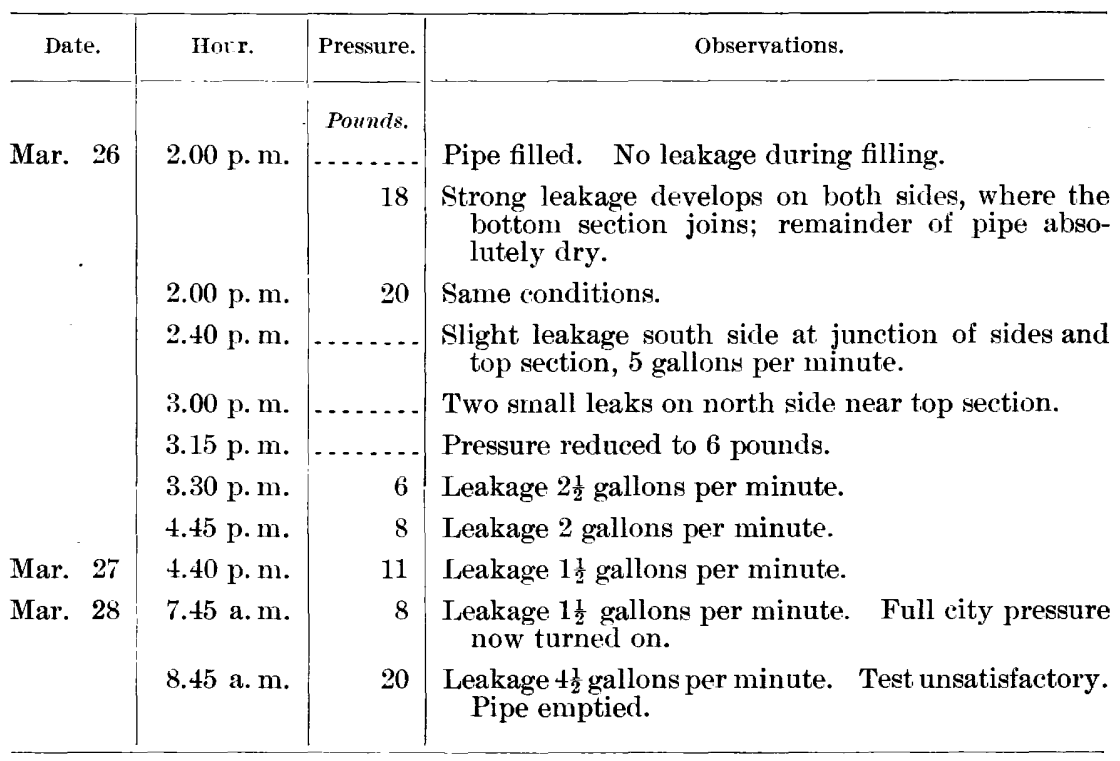

It is quite evident to the writer that washes of any kind, unless in the form of a glaze or a soluble glass, are ineffective for making a concrete pipe impermeable. Even if they'were effective at first, the coating, being so thin, would soon be worn away by the high velocity of the water, which is necessary for economy in most projects in the reclamation work.

PIPE NO. 7 .

Pipe No. 7, Test 1.

The pipe was composed of 1 part cement, one-half part lime paste, 3 parts sand, and 6 parts small gravel. It was completed on October 17, 1903 , and was well seasoned with water for several days after completion. It remained undisturbed where it was made.

On June 13, 1904, about 100 pounds of fine clay were placed in pipe No. 7 and the heads fastened on the ends of the pipe. 
Test 1 of pipe No. $\%$.

\begin{tabular}{|c|c|c|c|}
\hline Date. & Hour. & Pressure. & Observations. \\
\hline \multirow[t]{2}{*}{ June 13} & 3.30 p. m. & & Water turned in. \\
\hline & 5.00 p. m. & 2 & $\begin{array}{l}\text { Pipe commenced to leak on bottom. Inflow re- } \\
\text { duced to allow the pipe to fll slowly during the } \\
\text { night. }\end{array}$ \\
\hline \multirow[t]{2}{*}{ June 14} & 8.00 a. $\mathrm{m}$. & & $\begin{array}{l}\text { Pipe leaking badly. Leakage very muddy from } \\
\text { stirring up of clay. Clay stirred all day. }\end{array}$ \\
\hline & 4.45 p. $\mathrm{m}$. & & Pipe full and leaking like a sieve. \\
\hline \multirow[t]{2}{*}{ June 15} & 8.00 a. $\mathrm{m}$. & & No change. \\
\hline & 5.00 p. m. & & Water turned off; clay stirred. \\
\hline \multirow[t]{4}{*}{ May 16} & 8.00 a.m. & & $\begin{array}{l}\text { Water turned on; } 3 \text { hours required to fill pipe, } \\
\text { showing amount of leakage during night. }\end{array}$ \\
\hline & 11.00 a.m. & 2 & Pores closed up somewhat. \\
\hline & 2.00 p.m. & 0 & No pressure. Increased leakage. \\
\hline & $5.00 \mathrm{p.} \mathrm{m}$. & & Water turned off for night. \\
\hline \multirow{3}{*}{ June 17} & 10.40 p. m. & & $\begin{array}{l}\text { Pipe full, showing less leakage than on previous } \\
\text { night. }\end{array}$ \\
\hline & 10.40 p. m. & 4 & \\
\hline & 10.45 p. m. & 3 & $\begin{array}{l}\text { Remained at this pressure all day. Clay stirred } \\
\text { constantly. Pressure left on all night. }\end{array}$ \\
\hline \multirow[t]{2}{*}{ June 18} & 8.00 a.m. & 3 & $\begin{array}{l}\text { Considerable laitance. Number of clay streaks on } \\
\text { outside of pipe. }\end{array}$ \\
\hline & 3.30 p. m. & & Pipe emptied. \\
\hline
\end{tabular}

This pipe was tested for six days, and the closing up of the pores by lime deposits and clay combined apparently did not raise the pressure more than 3 pounds. During all this time the pipe leaked so badly as to demonstrate its entire unfitness for practical purposes. This experiment will serve to give an idea of the value of clay for stopping up the pores of concrete under the pressure of water.

Pipe No. 7, Test 2.

When the heads were removed from the pipe on the completion of the first test, the inside of the pipe was thoroughly washed to remove all traces of the clay, and on June 21 a plaster composed of 1 part cement (Ideal), 1 part marble dust, and 1 part fine screened sand was placed about one-fourth inch thick on the inside surface of the pipe for a length of 17 feet from the east end.

The remaining 3 feet of inside surface at the west end of the pipe was covered with Richards plaster of same thickness (one-fourth inch). 
The plaster was kept well moistened till noon, when a thick grouting of equal parts of cement and marble dust was painted over the plaster so as to fill up all the places where the trowel had pulled and a few checks had developed by too quick setting. This plaster and wash was kept well moistened until June 25 , when at $1 \mathrm{p}$. $\mathrm{m}$. the heads were put on and filling commenced.

At 3 p. m. there was great difference between this filling and the previous one, as there was no sign of leakage up to this time, and the pipe was about half filled.

At $5.10 \mathrm{p}$. m. the pipe was filled, and when the air pipe was closed the pressure slowly rose to 14 pounds, and in a few minutes the pipe leaked freely over most of its surface. Most of the leakage came through the bottom layer, and at $5.25 \mathrm{p} . \mathrm{m}$. the gage had dropped to 11 pounds. The pressure was allowed to remain on full till Monday morning.

June 27 , at 8.30 a. m., the gage registered 12 pounds, and the leakage was nearly 7 gallons per minute. The pressure was reduced to 5 pounds, and kept at that for the remainder of the day.

June 28 , at 8 a. m., the pressure had risen to 7 pounds during the night, and the leakage amounted to 3 gallons per minute.

The pressure was now turned on full, but the gage rose to only. 13 pounds, and in a few minutes dropped to 12 pounds; the bottom leaked as freely as before, though the sides and top did not leak as much as before.

It seems strange that the bottom part of this pipe should leak so badly, as in the other pipes the top and bottom sections, which were tamped in the line of pressure, leaked much less than the sides, which were tamped at right angles to the lines of pressure. The pressure was kept on full until noon. when it was reduced to 5 pounds, and held at that during the balance of the day and night.

On June 29 the pipe dried off a good deal under the reduced pressure, but the bottom leaked freely, and the top was moist in spots, while the sides were practically dry. Considerable laitance had formed where the water had leaked out and run down over the sides.

On June 30 the pressure at $8 \mathrm{a} . \mathrm{m}$. was 7 pounds and there was no material change in the action or appearance of the pipe, and when full pressure was put on the leakage was just as great as before.

The pipe was kept filled and under pressure of about 5 pounds until July 8; the city pressure was turned on occasionally, but the greatest pressure attained during this time was 15 pounds. All of the leakage of consequence was through the bottom section.

As this pipe leaked too much for practical purposes the water was turned off and the experiment concluded. 


\section{SUMMARY OF FIRST Ig TESTS.}

In looking over the results of the first 19 tests one thing seems sure-any pipe of this diameter and of great length would have many imperfections, many of which can not easily be avoided. The greater part of the leakage in nearly every case in these tests came from the tamping seams, and by this method of constructing the pipes these seams are almost a necessity. If there are to be seans at all, would it not be better to make them where they can be seen and made tight against leaking, so that more attention may be given to the remainder of the pipe, both in the material of which it is composed and in the placing and tamping of this material afterwards? The great difficulty in the way of making a large pipe of steel concrete continuous is that there are not only longitudinal tamping seams from short delays necessarily incident to this method of construction, but there are in addition cross seams wherever the work may stop for the night or for a day or more, for Sundays, holidays, or on account of bad weather or other unforeseen causes.

This naturally leads to the conclusion that the pipe might be more easily and economically made in short joints, and put together in the trench afterwards. By this means the tamping could be done continuously in each joint, so that there would be no leakage from tamping seams between joints, and special attention could be given to the joints, in order to render them water-tight under ordinary pressure.

A longitudinal seam is much more likely to leak than a vertical seam in pipe under pressure, because the pressure tends to open the longitudinal seam while it does not necessarily tend to open the vertical seam unless the pipe is built on a vertical curve, and this must be guarded against or provided for, if necessary, by taking up the longitudinal strains with steel rods or cables. This method would allow more care to be taken with the mixing and placing of the material and the tamping of it, and would probably result in a much more perfect pipe between joints. There are, however, many practical difficulties in the way of constructing such a pipe of large diameter and great thickness of shell. One of the principal difficulties is to hold the lengths of pipe together till the connection can be made. Anotber is the handling and placing of such heavy pieces of pipe without injuring them; a third difficulty is that of making a water-tight joint without creating a rough or uneven surface in the waterway.

To put all these matters to a practical test another pipe was constructed during the months of May and June, 1904. This pipe, which is called No. 8, was built in four pieces, each 5 feet in diameter inside, with a shell 6 inches thick, and with steel armor, as in the other pipes, in the center of the shell, and each piece was 5 feet long. 
PIPE NO. 8.

\section{COMPOSITION.}

The composition of the sections of pipe No. 8 is as follows:

Section 1 was composed of Gillingham cement, 4 cubic feet; marble dust, 1 cubic foot; fine sand, 3 cubic feet; gravel, 20 eubic feet; or, 1 part cement, 1 part sand, and 5 parts gravel. The cement and marble dust were mixed through a fine screen, then mixed with the gravel and sand and turned six times dry, then turned four times wet. The concrete was so made that water came to surface after long tamping.

Section 2 was composed of Gillingham cement, 4 cubic feet; marble dust, 1 cubic foot; sand, 3 cubic feet; gravel, 20 cubic feet; lime putty, 3 gallons. The cement and marble dust were mixed as in section 1. Lime putty, passed through fine screens and dissolved in 12 gallons of water, was added during wet mixing. The material was mixed the same number of times as that for section 1 , but it was made wetter.

Section 3 had the same composition as section 2 , except that to lime putty was added an equal amount of Richards putty.

Section 4 was composed of Ideal cement, 4 cubic feet; marble dust, 2 cubic feet; sand, $t$ cubic feet; gravel, 20 cubic feet-well screened and mixed. The material was dry mixed four times, wet mixed three times; 12 gallons of lime putty diluted in 24 gallons of water were added for wet mix.

All of these joints were made by continuous tamping, and every possible care was exercised to produce a good piece of work. They were all well seasoned by constant wetting and protected from the rays of the sun. The sections were made with a projecting bead at one end and a corresponding groove at the other end, so that the bead on one section would fit into the groove on the next section. In addition to this arrangement, a semicircular trench about 1 inch in diameter was left in the bead at one end, and another in the groove at the other end, so that when two sections are placed together these two semicircular trenches will form one circular opening 1 inch in diameter running clear around each joint. When the sections are pulled tightly together this opening can be filled up with cement grout or with any fluid material which may be decided upon as adding to the impermeability of the joint.

Fig. 2 shows the arrangement of sections before joints are closed. These sections were made with the intention of having six longitudinal steel rods run through them, to be fastened with sleeve nuts joining the ends of these rods in adjacent sections, large niches being left on the inside of the pipe at each joint where the sleeve nuts could be tightened. This arrangement would not work satisfactorily and was abandoned for a much simpler one. Through each section of pipe is 
run lengthwise six pieces of three-fourths-inch gas pipe, which serve as guides for the rings of steel, to which they may be fastened with copper wire. The sections being all made on one form, these pipes can be kept so closely to their proper position that there is no difficulty in running a piece of one-half-inch wire cable through them when the sections are placed in position for jointing.

The sections are laid as closely together as may be necessary to allow the mortar for the joint to be put in place between them, and are then drawn together by fastening cables through a wooden frame at

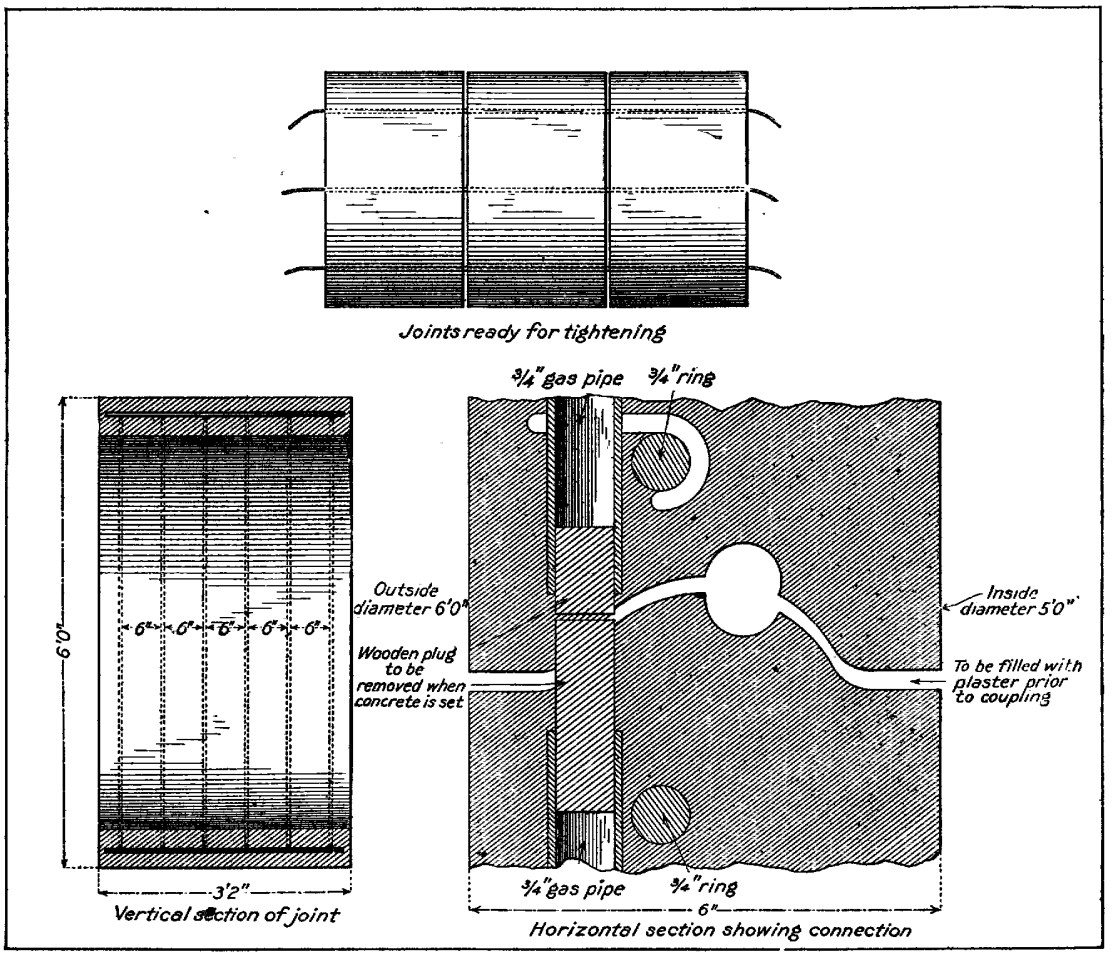

Fig. 2.-Sections of pipe showing methods of connection.

one end of the sections to be joined, and tightening up at the other end by a jackscrew working between two wooden frames, one of which rests against the last section, the other having the ends of the cables fastened to it with clamps, which can be readily removed when the joints are well closec. In the case of pipe No. 8 , four sections were tightened up at the same time, and there was no difficulty in bringing the sections together with this length of pipe (20 feet). By this method it would be necessary to have at the end of each 20 feet, or whatever length proved practicable for tightening, a special screw-end rod con- 
nection for the cables, about 2 feet long, so that the cable for the next length of pipe might be easily connected with that already tightened. It is most important that the ends of the sections should be made square with the longitudinal axis of the pipe.

Pipe No. 8, Test 1.

On July 28, 1904, this pipe, composed of four sections, was filled with water at $11.30 \mathrm{a} . \mathrm{m}$. During the filling section 3 showed a little sweating near the bottom, caused probably by a small crack made while this section was being rolled to its proper place, and all the joints showed a little moisture through the openings that run round the joints and that were recently filled with grout. This grout was composed of 1 part cement, one-fourth part marble dust, and 1 part sand. The joints and niches inside were all filled with Richards mortar. When the air pipe was closed the pressure rose to 15 pounds. Section 1 showed a slight sweat in a short time, but no pinholes, and it was fully half an hour before it became moist over most of its surface. In one hour it was sweating all over.

Section 2 gave about the same results as section 1 until the pressure had been on for ten minutes, when it cracked in three places at the south end for a distance of about 1 foot, and the water leaked out so fast that the pressure would not go above 20 pounds. In one hour the whole surface was sweaty. Section 3 showed sweat developing soon after the pressure was turned on, and in fifteen minutes had a general sweat that at 19 pounds increased to a strong drip.

Section 4 showed absolutely no leakage or sweat for half an hour after being filled, then a slight sweat started on the top, and in one hour this sweat had spread over about one-fourth of its surface. This section was made with Ideal cement.

All the joints sweated a little through the pockets where the grouting was yet fresh and slightly checked, but at no part of the joints did the leakage amount to a flow.

At $2 \mathrm{p} . \mathrm{m}$. there was not much change except that sections 1,2 , and 3 were entirely covered with laitance under a uniform pressure of 18 pounds. Section 4 showed a slight increase of sweat but no laitance except close to the joints, where there was a strong sweat through the pockets.

At 4 p. m. conditions were not materially changed.

At $5 \mathrm{p} . \mathrm{m}$. the pressure was reduced to 8 pounds, and the pipe was left under that pressure all night.

On July 29, at 8 a. m., the gage registered 10 pounds, and as soon as full pressure was turned on it rose to 20 pounds and remained at that for several hours, when it dropped to 18 pounds. There was no change in sections 1,2 , and 3 , while section 4 showed a slight sweat 
over three-fourths of its surface and no laitance except at the joints. Sections 1 and 2 showed considerably more laitance than section 3 .

City pressure was kept on full, and at $5 \mathrm{p} . \mathrm{m}$. no material change was apparent in the pipes, except that section 3 did not seem to drip as much as at first. Section 4 still had one large dry space on each side. The pressure varied all day from 17 to 19 pounds. At $5 \mathrm{p}$. m. the pressure was closed down for the night to 10 pounds. On July 30 , at 8 a. m., the gage registered 12 pounds. When pressure was turned on full it rose to 18 pounds. Section 3 appeared to be closing up and section 4 had not materially changed. By damming up the flow from the pipe and segregating the leakage from section 2, which was badly cracked, it was found that the other three sections leaked nearly 2 gallons per nimute.

The water was then turned off and the pipe examined, and it was found that the cracks in section 2 extended clear through. They are supposed to have been caused by the sling which was used when turning the pipes over on their sides with the derrick.

Section 3 showed two checks inside on top, but they did not go clear through.

Sections 1 and 4 showed no cracks on the inside, while section 1 had several checks on the outside.

Section 4 had no checks either inside or outside. The Richards plaster in the inside joints was found to be good and firm and showed no disintegration. Before this pipe was broken up a jackscrew was placed under one end and the pipe was raised until it hung suspended at both ends. The joints were then examined and found to be in good condition. The pipe remained in this position for ten minutes, when the central joint opened one-sixteenth of an inch at the bottom but remained tight at the top. The cables had eridently stretched sufficiently to allow this action. The pipe was broken up about September 27 , and it was found that the cracks on the outside on section 1 , near the end where the leakage was so great, were caused by the omission of the last steel ring during construction, leaving a space of nearly 1 foot in length at that end without any strength except that of the concrete, which naturally could not stand the strain.

When the joints were broken it was found that there was not as good a bond between the grout and the pipes as there should have been. The core would sometimes adhere to one section of the cavity and make a clean break along the line of the other joint so as to show the shape of the mold. The plaster in the joints should be allowed to harden for at least two days before the grout is forced into the cavity; the grout may be made very wet. The hole should first be filled with water in which a little cement is mixed and allowed to stand filled for an hour, and then blown out and filled with grout. 
While this experiment was not at all satisfactory on account of the accident in handling section 2 , it shows that, with care and attention to details, this method of constructing pipes might be adopted in case no better one is found.

\section{SMALL PIPES.}

Some further experiments were made for the purpose of ascertaining the best mixtures for impermeable concrete, and for this purpose several small pipes were made with various mixtures and carefully tested.

These smaller pipes were all made in the same mold, each being 8

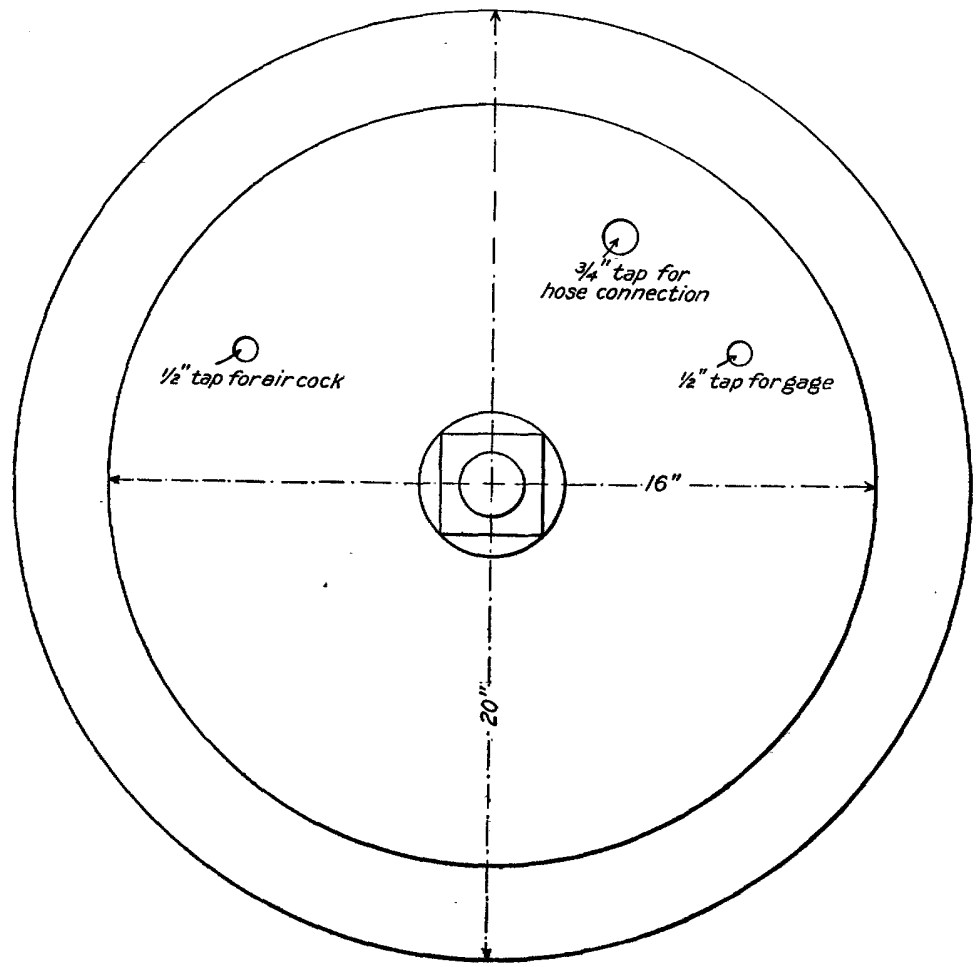

FIG. 3.-Elevation of end of small pipes, with cover, used for determining permeability of different mixtures of concrete.

inches in inside diameter, 6 inches in thickness of shell, and 18 inches long. The ends were made perfectly square to the axis and as smooth and true as possible. To the ends of these pipes were fitted small cast-iron disks, 1 inch thick, resting upon rubber-tire washers, vulcanized at the junction of the ends. The plates were drawn tightly on the washers by one central rod with a screw end to which a nut was fitted, substantially as shown in figs. 3 and 4 .

The upper plate had connections for pipe from water tap, for air, and for gage as in the larger pipes. 
Three of these pipes were made of each mixture, and nine different nixtures were tested. The three pipes for each nixture were marked "A," "B," and " $\mathrm{C}$," respectively.

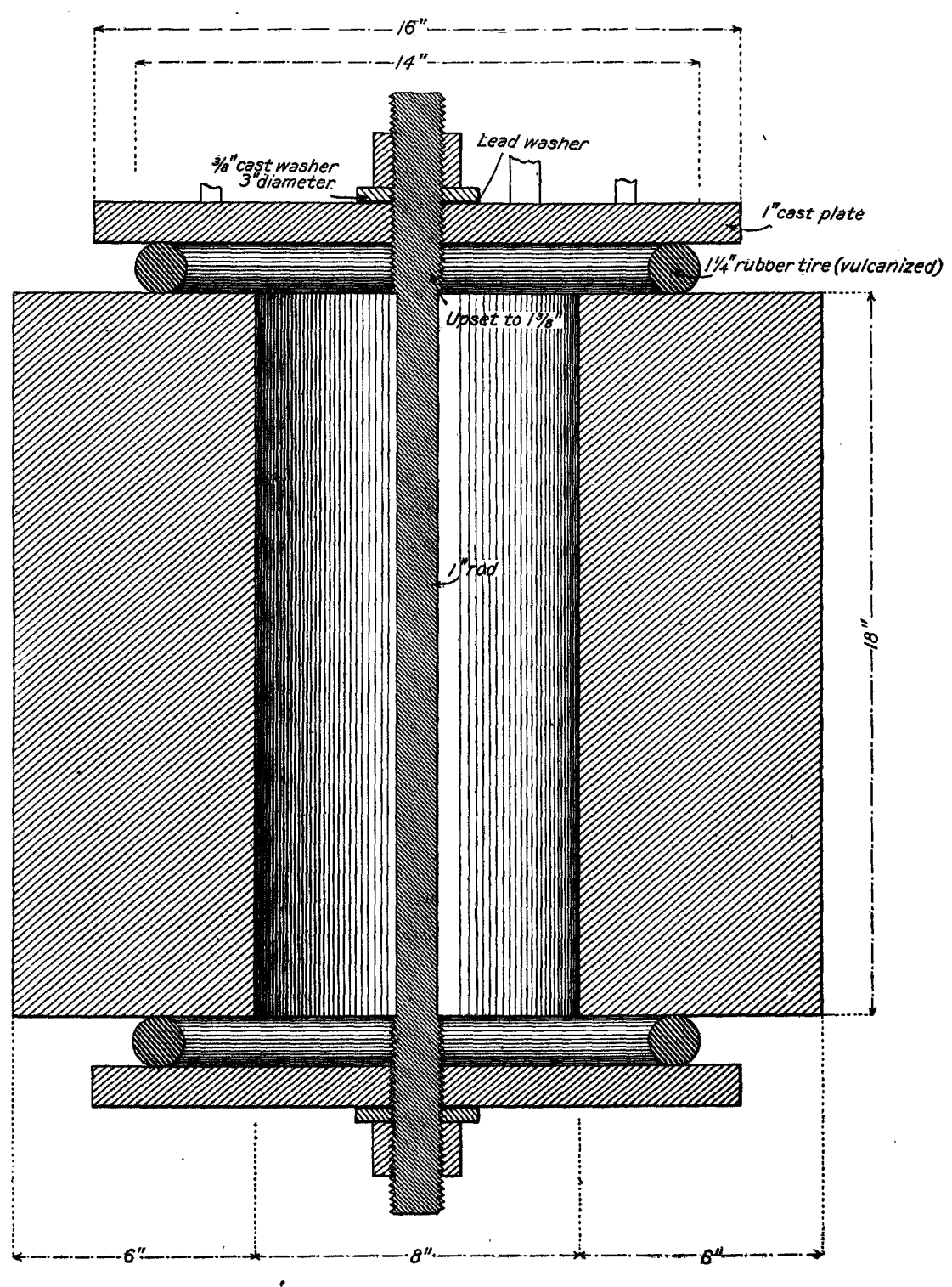

FIG. 4.-Horizontal section of small pipes used for determining permeability of different mix tures of concrete.

Mixture No. 1 consisted of sand 2 parts (screened through 14-mesh screen), gravel 3 parts (mixed sizes), cement (Ideal) 1 part, and marble dust 1 part-all measured loose. 
Pipe A, Mixture No. 1.

This pipe was made August 17, and brushed inside and out with a cement wash. It was kept well wet for several days until thoroughly seasoned. On October 19 water was turned on, the pressure varying from 40 to 56 pounds for six hours. During this time the pipe showed no sweat or leak, but in one of the sudden jumps of the pressure from 40 to 60 pounds the pipe burst and stopped the test. Owing to the fluctuation of the pressure in the water pipes this was not a very satisfactory test, but showed incidentally that the tensile strength of this mixture was at least 40 pounds per square inch.

Pipe B, Mixture No. 1.

This pipe was made on Angust 17. It was not washed with cement inside or outside, but was kept moist for three weeks and remained in the shade till October 20, when it was tested.

At $8.30 \mathrm{a}$. m. water was turned on and pressure allowed to rise to 40 pounds, and maintained as near that point as possible. In one hour a slight sweat showed near the bottom, and in four hours this sweat had spread over most of the surface. The pressure was then allowed to rise to 55 pounds, and a general sweat spread over the entire surface. This pressure was maintained for two hours more, and then the pipe burst during a sudden fluctuation of pressure from 45 to 62 pounds.

It was now decided to use two steel bands for clamping around the pipes during the tests, to prevent the bursting of the pipe under water hammer.

Pipe C, Mixture No. 1.

This pipe was made August 18, and kept in the shade and well moistened until Oetober 20, when it was tested. It was not washed with cement. At 3 p. m. water was turned on and the pressure regulated to 30 pounds. There was a flaw in the inside of this pipe caused by the material sticking to the core when the latter was being drawn out. The water seemed to enter this flaw, and caused a sweat at that place, and in two hours this sweat had spread over most of the surface of the pipe. At $5 \mathrm{p}$. $\mathrm{m}$. the pressure was turned off and the pipe left filled with water for the night.

On October 21 the pressure was kept at 35 pounds from 8 till 10 a. $\mathrm{m}$. The pressure was raised to 45 pounds, fluctuating between 43 and 55 pounds for two hours, during which time the pipe leaked $7 \frac{1}{2}$ gallons of water. The outside bands were now put on the pipe and the full city pressure turned on. The gage fluctuated between 43 and 62 pounds for the remainder of the day and until next day at noon, but there was no apparent increase in the amount of leakage. This pipe was not in good condition, but was tested for the sake of trying 
the effect of the steel bands on the outside in preventing bursting under fluctuating heads. In this case they seemed to answer the purpose, but in many of the succeeding tests they did not prevent the pipes from bursting under much lower heads.

As the object of the experiments was to ascertain at what pressure sweating commenced, and as this point was in nearly all cases less than 40 pounds, the breaking of the pipe at a higher pressure than this was not of so much consequence.

The composition of the various mixtures and the pressure at which the sweating first became visible are shown below.

\section{RESUlts OF TESTS OF SMALL PIPES.}

It is not claimed that these pipes would not have sweated and leaked under lower pressures maintained for a long time; but in nearly every instance the sweating showed at the recorded pressure inside of one hour from the time the water was turned on.

Mixture No. 1.-Sand 2 parts, gravel 3 parts, cement 1 part, marble dust 1 part.

Pipe A, no sweat under 55 pounds (washed inside and out with cement wash).

Pipe B, sweat at 40 pounds (not washed with cement).

Pipe C, sweat at 30 pounds (not washed and had flaw inside).

Mixture No. Q.-Sand 3 parts, gravel 4 parts, cement $\frac{2}{3}$ part, marble dust $1 \frac{1}{3}$ parts.

Pipe A, sweat at 60 pounds (washed inside and out with cement wash).

Pipe B, sweat at 45 pounds (not washed with cement).

Pipe C, sweat at 30 pounds (washed on inside with cement).

Miature No. 3. - Sand 3 parts, gravel 4 parts, cement $\frac{2}{3}$ part, marble dust $1 \frac{1}{3}$ parts, lime putty $\frac{1}{2}$ part.

Pipe A, sweat at 35 pounds (washed inside and outside with cement).

Pipe B, sweat at 30 pounds (not washed).

Pipe C, sweat at 30 pounds (washed inside with cement).

Mixture No. 4.--Sand 3 parts, gravel 4 parts, cement $1 \frac{1}{2}$ parts, hydrated lime $\frac{1}{2}$ part.

Pipe A, sweat at 30 pounds (washed inside and out with cement).

Pipe B, sweat at 35 pounds (not washed).

Pipe C, sweat at 35 pounds (washed inside with neat cement).

Mixture No. 5.-Sand 3 parts, gravel 4 parts, cement 1 part, marble dust 2 parts, lime putty $\frac{1}{4}$ part.

Pipe A sweat at 50 pounds (washed inside and out with neat cement).

Pipe B sweat at 35 pounds (no wash).

Pipe $\mathrm{C}$ sweat at 40 pounds (washed inside with neat cement).

Mixture No. 6.-Sand 2 parts, gravel 5 parts, cement 1 part, marble dust 1 part, Richards mixture 1 part.

Pipe A sweat at 40 pounds (not washed).

Pipe B sweat at 40 pounds (not washed).

Pipe $\mathrm{C}$ broke at 40 pounds. Without sweat for 45 minutes. (Not washed.)

Mixture No. \%.-Sand 2 parts, gravel 5 parts, cement 1 part, marble dust 1 part, lime putty $\frac{1}{2}$ part (with Richards mixture).

Pipe A sweat at 35 pounds (no wash).

Pipe B sweat at 38 pounds (no wash).

Pipe C sweat at 40 pounds (no wash).

Mixture No. 8.-Sand 2 parts, gravel 5 parts, cement 2 parts, hydrated lime $\frac{1}{2}$ part, marble dust $\frac{1}{2}$ part. 
Pipe A sweat at 35 pounds (no wash).

Pipe B sweat at 23 pounds (no wash).

Pipe $\mathrm{C}$ sweat at 23 pounds (no wash).

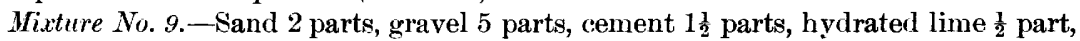
marble dust 1 part.

Pipe A sweat at 40 pounds (no wash). This pipe stood 65 pounds without breaking.

Pipe B sweat at 41 pounds (no wash). This pipe stood 57 pounds' pressure without breaking.

Pipe C discarded on account of flaw.

It is evident from these experiments that the impermeability of the concrete itself in a steel-concrete pipe must not be depended on too much, but it is better to cover the inside surface of the pipe with a thick coat, or probably better still with several thin coats of impervious mortar. This mortar must be soft and plastic when first placed on the pipe. The Richards plaster seems to be the nearest approach to this ideal plaster that has been found in these experiments.

The experiments on the small pipes were not carried out by the writer, who, on account of other duties, was unable to direct them. The assistant in charge of the experiments was a very careful, painstaking, and practical man of long experience in concrete work, and the experiments are given for what they are worth.

This entire subject is a most complex one, and it is realized that the results of these experiments are somewhat disappointing. It is hoped, however, that what little has been done may serve as a beginning for further experiments.

\section{CONCLUSIONS.}

The following precautions in making concrete pipes to withstand water pressure are suggested:

1. Do not allow the sun's rays to touch the concrete when it is being mixed and placed in the form. If necessary build a shed over the work.

2. If the steel-concrete pipe can not be made continuously by machine, do as much of the hand tamping as possible in radial directions. When the tamping must be done at right angles to the radius of the pipe, either in longitudinal or circumferential directions, avoid as far as possible the formation of seams or cleavage planes from delays in placing the forms and adding fresh material. By making the concrete very wet, delays will not be so dangerous as in the case of dry concrete.

3. Be careful in tamping not to spring the longitudinal rods, and use as few of these as will suffice to hold the circumferential rods in place, except in case of vertical curves in the pipe, when additional rods or steel cables must be used on the longer side of the curved part of the pipe.

4. Do not depend upon the tensile strength of the concrete, but 
make the steel rods of such size and distance apart as will insure no greater stretch of the steel than 0.04 inch in any rod from the maximum pressure to which the pipe is to be subjected.

5. Make the inside diameter of the pipe $1 \frac{1}{2}$ inches larger than required, to allow space for putting two coats of plaster on the inside.

6 . As soon as the pipe is completed give the inside one coat of plaster one-half inch thick, composed of 1 part cement to $1 \frac{1}{2}$ parts of sand, and a small quantity of lime paste, thoroughly cooled, to retard setting. Keep pipe well wet ahead of the plastering. When this coat, which may be left rough, is dry, put on another coat about one-fourth inch thick of plaster composed of 1 part of sand to 1 part of cement. This coat should be troweled to a smooth surface, and when it is dry the entire inside surface of the pipe should be covered with a thick wash of fine cement and water.

7. Provide for drainage of water which may leak when the pipe is first filled, so that sufficient water may not remain in the trench to soften the ground under the pipe.

8. Bury the pipe under the ground so that there will be in no place less than 2 feet between the top of the pipe and the natural surface of the ground.

9. In very cold climates provide means for draining the pipe, so that it can be emptied at the end of each irrigating season.

10. The soap and alum mixture may be used to advantage in making the concrete, but reliance for impermeability must be placed on the plastering rather than on the material of the pipe.

11. Do not use steel-concrete pipes for heads over 70 feet, except for short distances, where a 100 -foot head might be used by taking special precautions.

It may be asked why, in view of the fact that a head of 70 feet is likely to crack a 5-foot steel-concrete pipe, it is recommended to build pipes of such diameter, for use under such a head. It may be answered that a steel-concrete pipe with a crack and a small, gradually decreasing leakage may be, and probably is, much more durable than a pipe made of steel, or of wood with steel bands or rods, and the leakage, under ordinary circumstances, may not be as much as is now found in many lines of cast-iron pipes in our large cities.

Under ordinary conditions, in all of the reclamation projects where pressure pipes may be used, the pipes will probably be under uniform pressure for all of the irrigating season. It is highly probable that cracks formed in these pipes when under pressure will be filled up with sediment and lime deposits during the irrigating season, which generally lasts several months. If serious leaks occur during this season, the blow-off and drain pipes can be used to turn the water out of the pipe, so that it can be repaired inside, and during the winter 
time, when the pipe is empty, an excellent opportunity is afforded to examine and make repairs in the inside of the pipe.

A 5-foot pipe under 30 pounds pressure, or approximately 70 feet head, if made with 1-inch rods, instead of three-fourths-inch rods, with $3 \frac{3}{8}$-inch center distances, would cost about $\$ 2.50$ a foot extra, and the only gain would be that the stretch of the steel would be 0.023 inch, instead of 0.040 inch for the three-fourths-inch rods. Theoretically, when steel-armored concrete pipe is subjected to internal pressure, the materials of which it is composed must yield or stretch within certain limits. As the stretch of concrete is so small that it has never been measured, we must rely upon the steel to take up the stresses caused by the internal pressure in the pipe. If a steel-concrete pipe is designed to bear with safety 30 pounds per square inch internal pressure, and the steel in the pipe is calculated to take up all the stress due to this pressure, with a factor of safety of 4 for steel of an ultimate strength of 60,000 pounds, and if the pipe is 5 feet diameter inside, and the steel rods three-fourths-inch diameter, these rods would have to be spaced 7.33 inches from center to center.

Let us determine what the stretch in this steel would be in one rod under these conditions.

The stretch in inches = total stress in pounds on 7.33 inches in length of pipe $\times$ original length in inches $\div$ modulus of elasticity in pounds per square inch $\times$ area in square inches; therefore stretch $=$

$$
7.33 \times 30 \times 30 \times \frac{204}{35,000,000 \times 0.44}=0.09 \text { inch nearly. }
$$

It is probable that this amount of stretch in the steel would cause one or more cracks along the full length of the pipe. If, however, the amount of steel is doubled, the stretch would be reduced by onehalf, but this makes the pipe more expensive.

There would still be a stretch of $0.04 \mathrm{inch}$, and the consequences of this stretch might be guarded against by plastering with some material which would be more plastic than ordinary concrete, or by another method mentioned hereafter.

If this steel were distributed over the full length of the pipe in the shape of a sheet-steel riveted pipe, it wo:ld give thickness of $\frac{0.44}{3.66}=0.12$ inch for the steel, and this pipe, if double riveted, would have a factor of safety of 5.6. This thickness is really more than is necessary for safety, but not more than is necessary for rigidity of form in a steel pipe of 5 feet diameter if used alone, nor for a steel-concrete pipe under the assumed pressure if the stretch is taken into account.

There can be no question that a steel pipe inside a concrete pipe would be tight, but it would be useless to put a lining of concrete inside the steel, as the concrete would certainly leak some, and the steel would be little better protected on the inside from the action of the water 
than if there were no concrete inside. It would, however, be protected from scouring, and a ring of concrete outside the steel would protect the outside of the steel from the action of injurious salts, acids, etc. A better pipe, however, would be a wooden pipe with steel bands, which can be made perfectly continuous, smooth, and true inside, with a ring of concrete placed around it after the wood is thoroughly saturated and the leaks all closed up. This would be an expensive pipe, but it is believed that it would be as nearly an ideal pipe for a warm climate as could be made. With a factor of safety of 4 for the steel rods, the amount of steel would be reduced to half of that in the concrete pipe, and in the case of 30 pounds pressure this would amount to a three-fourths-inch rod 17 feet long for each 7.33 inches in length of the pipe, or $\frac{17 \times 1.5 \times 12}{7.33}=t 1$ pounds of steel per linear foot of pipe.

Concrete in a ring 3 inches thick around wood pipe would amount to $\frac{18}{4}=4 \frac{1}{2}$ cubic feet per linear foot, so that the amount of money saved on the steel by using a wooden pipe would probably pay for the concrete used in covering it.

For a comparison of cost, then, we could have a wooden pipe with bands spaced for a factor of safety of 4 , and 3 inches of concrete outside, as against a steel-concrete pipe with twice the number of bands and 6 inches of concrete. With steel at 4 cents per pound in place, concrete at 40 cents per cubic foot in place, and lumber at 7 cents per foot B. M. in place, the cost of these pipes would be about the same, and there is little doubt that the wooden pipe with a concrete envelope would be the better and more lasting pipe.

Another method for getting rid of the injurious effect of the stretch in the steel in a steel-concrete pipe (with a factor of safety of 4 for the steel rods) would be to make two well-defined joints in the concrete in a horizontal plane through the center and running the full length of the pipe.

A continuous sheet-steel dowel could project 2 or 3 inches into the concrete in each half of the pipe, and when the pressure came on the inside the stretch would probably take place at these joints and thus prevent all other longitudinal cracks from forming.

This dowel, which might be one-eighth by 6 inches, could be made in long lengths, overlapping a little at the ends and fastened by wire to the rods to keep it in its proper place. The concrete in the lower half of the pipe would end in a smooth, horizontal plane at the center line of this dowel on each side, and this plane might be allowed to harden for twenty-four hours, so that when the upper half of the pipe was made there would be a well-defined crack on each side. Of course this would increase the area subject to inside pressure by a small amount on each side, but this would be true of any other longitudinal crack. 
It seems probable that this would prevent any other cracks forming, but it would be necessary to try this experiment before building any large amount of pipe on this assumption.

The durability of steel rods of large diameter, such as were used in these experiments, is yet undetermined, as the time between placing these rods in the concrete and the breaking up of the pipes was too short to afford reliable data for conclusions on this subject.

When the pipes were broken up none of the rods exhibited any appearance of rust, except one, which showed, at a point where there was a large and long-continued leak in the pipe, a small rusty place, about $1 \frac{1}{2}$ inches long, all around the rod. The pipe in which this occurred was lined with a mortar mixed with sal ammoniac and iron filings, and the presence of the sal ammoniac would naturally account for the rust.

Instead of steel rods electrically welded galvanized wire might be used for armor in concrete pipe. This wire is now manufactured in the United States, and could be used if the pipe were made in joints. It would not be suitable, however, if the pipe were made continuously, as in these experiments, on account of the difficulty of tamping and the stretch of the steel, and the consequent cracking of the conerete would still occur, so that the amount of wire needed in the hoops would probably make it too expensive to be considered.

If many of the results of these experiments have been negative, it may be some consolation to remember that it is sometimes quite as important to know how not to do a thing as to know how to do it. 


\section{N D E X.}

Page.

Alkali soil, effect of, on steel pipe......... 9,10

Alum, use of.

use of, advantage in

in plaster lining

Annales des Ponts et Cha M. R. Feret in

Ashes, test of, in stopping leaks.

Cement, Gillingham, use of ........... 13,14,46

Cement, Ideal, use of, in pipes...... 14, 15, 46,51 use of, in plaster.................... 31,43 in wash

Clay, effectiveness of, in closing pores...... test of, in stopping leaks ............... use of, inside pipe ................. 37,4

to render pipes impervious.........

Climate, effect of, on wooden pipe

Coal tar, use of, in plaster of plaster linings $\ldots \ldots \ldots \ldots \ldots \ldots \ldots, 18,19,21$ of small pipes ...................... 51,53 of tested steel-concrete pipes.......... 13-15

Conclusions from experiments ........... 54-58

Concrete, composition of, in pipe ...... 13-15, 46 discussion of, in Proc. Am. Soc. Civ. Eng. first test of method of tamping................ 16,54 mixing of, in making pipes .......... 17,46 porosity of .......................... tensile strength of test of impermeable mixtures for....... use of soap in.

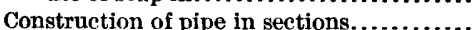
of pipes, suggestions for............... of steel-concrete pipes.

\section{1}

.

Iro I}

Jon

Joints, how rendered impermeable ........ 46,49 tightening of, by wire............... 58

Laitance, composition and occurrence of .. $\quad 12$ effect of, on pipes .................... 21 occurrence of, on pipes..... 20,23, 24, 39, 44,49 Leakage, amount of, in pipes without plaster....................... 28 cause of, along tamping seams ......... $\quad 36$ drainage of, provided for............. effect of clay in stopping ............ 37,43 general origin of $. . \ldots \ldots \ldots \ldots \ldots \ldots \ldots \ldots . \quad 45$ measurement of ..................... 24,25 by weir......................... 24 possible effect of, on foundation of pipe. $\quad 20$ reduction of, by time.................. 20 variance of, in different pipes with same pressure.................... 27

Disk, details of, view of................. 18

Disks ready for test, view of................ 16 use of, in testing pipes ............. 17, 18

Drainage from leakage provided for ....... of pipes in cold weather................

Dry mixture, use of, in pipe..............

Durability of steel pipe.................. 9, 10 of steel rods ....................... 58

Efflorescence, deposition of, on concrete pipes under water pressure..... 11, 12

Elastic lining, need of ................... Elastic paint, use of, on pipe. 29 10 10

$\begin{array}{lr}\text { Gas pipe, use of, in concrete pipe ......... } & 47 \\ \text { Gillingham cement, use of, in pipes. } \ldots . . & 13,14,46\end{array}$

Glaze, need of, inside pipes under pressure. 41,42

Gravel, porosity in mixture of ............ $\quad 20$

effectiveness of, in joints of pipe ....... 49

use of, to cement joints .............. 46

Head of water, limit of, for steel-conerete

Ideal cement, use of........ 14, 15, 31, 41, 43, 46,51

49
increase of, with age ..................

test of, in small pipes................ 50,53

ten, use of, in wash ................... 39

g., advantage of use of............ 
Mixture, dry, use of, in pipe ............. pressure

Paint, elastic, use of on pipe.

Paint, P. and B., use of............... 21, 35

Paint, waterproof, use of ................ 21 effectiveness of .................... 35, 36

Permeability of concrete pipe, MeIntyre and True on.................

Pipe, construction of, in sections........46,47 construction of, method of, view of .... end of, being raised, view of.......... section of, showing direction of tamp-

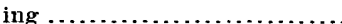
sections of, showing method of connection.

under test, view of ...................

with disks set ready for test, view of...

Pipe, concrete, permeability of............

Pipe, steel, durability of ................ 9,10

Pipes, cost of, computed................ 57

cracks inside of $\ldots \ldots \ldots \ldots \ldots \ldots \ldots \ldots 20,24$

draining of, in cold weather .......... $\quad 55$

effect of velocity of water on ........... 42

method of finishing, view of ......... 16

methods suggested for construction of . $\quad 57$

mixing of concrete for $\ldots \ldots \ldots \ldots \ldots \ldots, 17,46$

placing of, underground ..............

under pressure, need of glaze in......... 41, 42

use of elay in .................... 37,42

Pipes, concrete, necessity of plaster for.... 28,54

Pipes, pressure, different kinds used ....... 9-11 need of, in Reclamation Service....... 9

Pipes, small, construction of ............ 50-53

effect of water hammer on ............ 52

elevation of end of, figure............ 50

horizontal section of ................. 51

See also Steel pipes; Steel-concrete pipes; Wooden pipes.

Plaster, advantage of softness in ..........

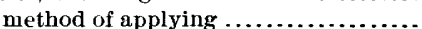
necessity of use of $\ldots \ldots \ldots \ldots \ldots \ldots \ldots \ldots, 28,54$ use of alum in . use of coal tar in...................... use of iron filings in.................. use of lime with ...................... use of linseed oil in................... use of sal ammoniac in ................. use of soap in. .........................

Plaster, elastic, need of ...................

Plaster, Richards, effectiveness of........... use of ................ 25, 26, 39, 43,46,48,49

Plaster, waterproof, test of ............... 38

Plaster linings, composition of ........ 18,19,21 effectiveness of

Porosity, effect of clay on .................. effect of lime on ...................... in concrete. of concrete, paper by Feret on ......... of mixture of gravels of different sizes. relation of, to leakage.

Pressure, effect of, on difterent porosi effect of, on paint .........................

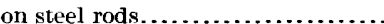
on wash

in city water mains, change of.........
Pressure, measure of bursting force of .....

Page.

taken up by steel rods.............. 30

use of, from water mains........... 20,21

Pressure pipes, different kinds used. . . . . . . 9-11 need of, in Reclamation Service ...... 9

Pump, use of, on pipe ................ $\quad 25$

Pumps, little used in testing ........... 21

Reclamation Service, use of pressure pipes

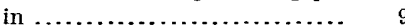

Richards, C. E., presence of, at test of his

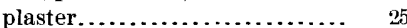
wash and plaster of $\ldots \ldots \ldots \ldots \ldots \ldots \ldots . \quad 38$

Richards plaster, effectiveness of .......... use of $\ldots \ldots \ldots \ldots \ldots \ldots \ldots 25,26,39,43,46,48,49$

Rod, central, view showing, with details .. $\quad 18^{:}$

Rods, longitudinal, care of, in tamping... 54 cracks along ........................ 37

Rods, steel, durability of ............. 58 effect of sal ammoniac on ........... 34 factors of safety in $\ldots \ldots \ldots \ldots \ldots \ldots \ldots 56,57$ pressure on ..................... 30 proper size of, in steel-concrete pipe ... 56 stretch of, under pressure............ 56

Rubber gasket, accident to ............ 24 use of, on pipes............... 17, 18 Safety, factors of, in steel rods ......... 56, 57 Sal ammoniac, effect of, on steel rods..... 34 use of, in plaster .................. $\quad 9$ in wash

Sanders, W. H., supervision of construction of pipes by ................ 13,:0 Sections, horizontal, of small pipes ....... 51 small pipes. See Pipes, small.

Soap, use of, advantage in ............. 55 use of, in pipe ...................... 13

in plaster lining............... 19

Steel pipe, comparison of, with steel-concrete pipe ................... 55

effect of soil on .................... 9,10

construction and use of $\ldots \ldots \ldots \ldots \ldots, 9,10$

Steel rods. See Rods, steel.

Steel-concrete pipes, apparatus for testing of ...................... 17,18

comparison of, with steel pipe and wooden pipe ............... 55

composition and construction of ..... 11-17 composition of those tested ...... 13-15,46 disadvantages of $\ldots \ldots \ldots \ldots \ldots \ldots \ldots \ldots . . \ldots \ldots$ limits of water head for .............. 55 method of construction of .......... 15-17 relations of porosity, pressure, and leakage in ..................... 27 tamping of, in constructing ......... 16,54 Stretch in steel, injury from, avoided..... 57 in steel rods . ....................... 56 Stuffing box, use of, inside pipe to stir clay . $\quad 37$ Sun, effect of, on concrete under construction...................... $\quad 36$ injury from, in constructing concrete.. $\quad 54$ Sylvester wash, effectiveness of, in concrete pipe..................... $\quad 29$ effectiveness of, on inside of pipe ..... 35,36 use of ................... 21, 24, 35,41 Tamping, direction of, section showing... 16 method of, in concrete pipe ........... 54 in steel-concrete pipes........... 16 
Page.

3., Tamping seam, cause of leak from....... 36 causing of cracks by $\ldots \ldots \ldots \ldots \ldots \ldots \ldots 1,30$ leakage from

longitudinal and vertical compared... necessity of, in construction of large pipes

plan for avoidance of.

Test pipes, composition of

Tests, apparatus used for.

composition of pipes for

of small pipes, object of

of steel-conerete pipes. summary of

True, A. L., on permeability of concrete... Tufa elastic paint, use of

Underground position of pipes

Velocity, probable effect of, in water pipes.

Wash, directions for applying, by Trautwine.

effectiveness of, inside of pipes under pressure.

use of, without plaster.
Wash, use of iron water in

Page.

use of sal ammoniac in

31,39

Wash, waterproof, test of................ 38 see also sylvester wash.

Water, penetrating power of $\ldots \ldots \ldots \ldots \ldots \ldots . \quad 11$

Water hammer, effect of, on small pipes... $\quad 52$

Water mains, change of pressure in, during day

of city, use of pressure from.......... 20

Water pressure, efflorescence from........ 11, 12

limit of, for steel-concrete pipe ........ 55

Waterproof material in concrete, test of ... 28

Waterproof paint, effectiveness of, inside of

pipe ...................... 35,36

Waterproof wash and plaster, test of....... $\$ 8$

Weir, use of, to measure leakage of pipe ... $\quad 24$

Wire, use of, in jointed pipe ............ 58

Wire cable, use of, in pipe.............. $\quad 47$

Wooden pipe, advantages of............ 57 comparison of, with steel-concrete pipe. $\quad 55$ construction and use of ............... 10,11 effect of climate on................. 10 



\section{PUBLICATIONS OF UNITED STATES GEOLOGICAL SURVEY.}

[Water-Supply Paper No. 143.]

The publications of the United States Geological Survey consist of (1) Annual Reports; (2) Monographs; (3) Professional Papers; (4) Bulletins; (5) Mineral Resources; (6) Water-Supply and Irrigation Papers; (7) Topographic Atlas of United States-folios and separate sheets thereof; (8) Geologic Atlas of United States-folios thereof. The classes numbered 2, 7, and 8 are sold at cost of publication; the others are distributed free. A cireular giving complete lists may be had on application.

Most of the above publications may be obtained or consulted in the following ways:

1. A limited number are delivered to the Director of the Survey, from whom they may be obtained, free of charge (except classes 2, 7, and 8), on application.

2. Every member of Congress is allotted a certain number, from whom they may be obtained, free of charge, on application.

3. Other copies are deposited with the Superintendent of Documents, Washington, D. C., from whom they may be had at practically cost.

4. Copies of all Government publications are furnished to the principal public libraries in the large cities throughout the United States, where they may be consulted by those interested.

The Professional Papers, Bulletins, and Water-Supply Papers treat of a variety of subjects, and the total number issued is large. They have therefore been classified into the following series: A, Economic geology; B, Descriptive geology; C, Systematic geology and paleontology; D, Petrography and mineralogy; E, Chemistry and physics; F, Geography; G, Miscellaneous; H, Forestry; I, Irrigation; J, Water storage; K, Pumping water; L, Quality of water; M, General hydrographic investigations; N, Water power; O, Underground waters; P, Hydrographic progress reports. This paper is the eighteenth in Series $\mathrm{I}$, the complete list of which follows (all are Water-supply Papers thus far).

\section{SERIES I-IRrigation.}

Ws 2. Irrigation near Phoenix, Ariz., by A. P. Davis. 1897.98 pp., 31 pls. and maps. (Out of stock.) WS 5. Irrigation practice on the Great Plains, by E. B. Cowgill. 1897 . 39 pp., 11 pls. (Out of stock.) Ws ,9. Irrigation near Greeley, Colo., by David Boyd. 1897. 90 pp., 21 pls. (Out of stock.)

WS 10. Irrigation in Mesilla Valley, New Mexico, by F. C. Barker. 1898. 51 pp., 11 pls. (Out of stock.)

WS 13. Irrigation systems in Texas, by W. F. Hutson. 1898.68 pp., 10 pls. (Out of stock.)

WS 17. Irrigation near Bakersfield, Cal., by C. E. Grunsky. $1898.96 \mathrm{pp} ., 16$ pls. (Out of stock.)

WS 18. Irrigation near Fresno, Cal, by C. E. Grunsky. 1898. 94 rp., 14 pls. (Out of stock.)

WS 19. Irrigation near Merced, Cal., by C. E. Grunsky. 1899.59 pp., 11 pls. (Out of stock.)

WS 23. Water-right problems of Bighorn Mountains, by Elwood Mead. 1899.62 pp., 7 pls.

WS 32. Water resources of Porto Rico, by H. M. Wilson. 1899 . 48 pp., 17 pls. and maps. (Out of stock.)

WS 43. Conveyance of water in irrigation canals, flumes, and pipes, by Samuel Fortier. 1901. $86 \mathrm{pp} ., 15 \mathrm{pls}$. (Out of stock.)

Ws 70. Geology and water resources of the Patrick and Goshen Hole quadrangles, Wyoming, by G.I. Adams. 1902. $50 \mathrm{pp} ., 11 \mathrm{pls}$.

WS 71. Irrigation systems of Texas, by T. U. Taylor. $1902.137 \mathrm{pp}, 9$ pls.

WS 74. Water resources of the State of Colorado, by A. L. Fellows. $1902.151 \mathrm{pp} ., 14 \mathrm{pls}$.

WS 87. Irrigation in India (second edition), by H. M. Wilson. $1903.238 \mathrm{pp}, 27 \mathrm{pls}$. 
WS 93. Proceedings of first conference of engineers of the Reclamation Service, with accompanying papers, compiled by F. H. Newell, chief engineer. 1904. $361 \mathrm{pp}$.

WS 117. The lignite of North Dakota and its relation to irrigation, by F. A. Wilder. 1904. 59 pp., 8 pls.

WS 143. Experiments on steel-concrete pipes on a working scale, by J. H. Quinton. 1905. 61 pp.. 4 pls.

The following papers also relate especially to irrigation: Irrigation in Indi:a, by $\mathrm{H}$. $\mathrm{M}$. Wilson, in Twelfth Annual, Pt. II; two papers on irrigation engineering, by H. M. Wilson, in Thirteenth Annual, Pt. III.

Correspondence should be addressed to

The Director,

United States Geological Surver,

July, 1905.

Washington, D. C. 


\section{LIBRARY CATALOGUE SLIPS.}

[Mount each slip upon a separate card, placing the subject at the top of the second slip. The name of the series should not be repeated on the series card, but the additional numbers should be added, as received, to the first entry.]

Quinton, John H. I850-

蒫

... Experiments on steel-concrete pipes on a working scale, by John H. Quinton. Washington, Gov't print. off., I905.

61, iii p. illus., IV pl. $23^{\mathrm{cm}}$. (U. S. Geological survey. Water-supply and irrigation paper no. 143)

Subject series: I, Irrigation, 18.

1. Pipes.

Quinton, John H. I850-

... Experiments on steel-concrete pipes on a working scale, by John H. Quinton. Washington, Gov't print. off., 1905 .

61, iii p. illus., IV pl. $23^{\mathrm{cm}}$. (U. S. Geological survey. Water-supply and irrigation paper no. 143)

Subject series: I, Irrigation, 18.

1. Pipes.

\section{U. S. Geological survey.}

Water-supply and irrigation papers.

no. I43. Quinton, J. H. Experiments on steel-concrete pipes on a working scale. 1905 .

U. S. Dept. of the Interior.

see also

U. S. Geological survey.

IRR $143-05-5$ 
